\title{
Nano Aerosols Including Radon Decay Products in Ambient Air
}

\author{
Janja Vaupotič \\ Jožef Stefan Institute, Ljubljana \\ Slovenia
}

\section{Introduction}

Ambient air is composed of major constituents, nitrogen and oxygen, and small amounts of argon and carbon dioxide. Water vapour and trace gases are also present. It is, in fact, not a gas but an aerosol with suspended particulate matter. The particle sizes ranges from several $\mathrm{nm}$ for molecular clusters to about $100 \mu \mathrm{m}$ for fog droplets and dust particles. Particles larger than $100 \mu \mathrm{m}$ cannot stay suspended in air and may therefore not be considered as aerosols (Colbeck, 1998). Classification of aerosols with respect to their particle size differs depending on the purpose of use as well as the author (Wen, 1996; Colbeck, 1998; Turner \& Colbeck, 2008; Busek \& Adachi, 2008; Kumar et al., 2010b). Terms of ultrafine (<100 nm), fine $(<1000 \mathrm{~nm})$ and coarse $(>1000 \mathrm{~nm})$ particles are the preferred terms used by toxicologists and regulatory bodies. Aerosol scientists, on the other hand, refer mostly to different modes (Kumar et al., 2010b): nucleation (1-30 nm), Aitken (20-100 nm) and accumulation mode (90-1000 nm). Nevertheless, the borders are not strictly fixed and may differ from author to author. The term nano is not applied univocally either. Although it may refer to any particle of $<1 \mu \mathrm{m}$ size, it is reserved for particles of $<300 \mathrm{~nm}$ (Kumar et al., 2010b), <100 nm (Busek \& Adachi, 2008; Nowack \& Bucheli, 2001), <50 nm (Morawska et al., 2008), or even smaller (Anastasio \& Martin, 2001; Shi et al., 2001). In any case, monodisperse aerosols are very rare. They are mostly polydisperse with a particle size distribution which is mathematically described by either a differential or an integral distribution function $P^{\mathrm{N}}(d)$ (Wen, 1996). The latter is more often applied and, for number size distribution, expressed as:

$$
P^{\mathrm{N}}(d)=-\frac{\mathrm{d} C_{\mathrm{gen}}^{\mathrm{N}}}{\mathrm{d} d},
$$

where $C_{\text {gen }}^{\mathrm{N}}$ is the number concentration of particle with diameter $d$. Because of the wide range of sizes in polydisperse systems, logarithm of diameter is used instead, and Eq. 1 converts to:

$$
P_{\mathrm{L}}^{\mathrm{N}}(d)=-\frac{\mathrm{d} C_{\mathrm{gen}}^{\mathrm{N}}}{\mathrm{d}(\ln d)} .
$$


Similarly as for the number concentration, also size distributions of other property can be expressed, such as particle surface, volume, mass, activity (for radioactive aerosols) and others. For the same aerosol they appear to differ considerably from one another, in respect to both the number of peaks and peak positions in the particle size region (Colbeck, 1998; Turner \& Colbeck, 2008; Busek \& Adachi, 2008). For instance, the plot of the number distribution shows a maximum at smaller particle sizes than the plot of the volume (or mass) distribution, because the smaller particles, though abundant in number, have smaller volumes (smaller cube of diameter). For the same reason, the maximum in the surface distribution appears at larger particle sizes than that in the number distribution.

\subsection{General aerosols}

The term 'general' is used here to comprise all particles, carrying or not carrying radioactive elements (in our case radon short-lived decay products), although the contribution of the latter is minimal, as will be seen later. Atmospheric particles have natural and anthropogenic sources (Baltensperger \& Nyeki, 1998; Nowack \& Bucheli, 2001; Dobos et al., 2009; Kumar et al., 2010b). Forests and sea surfaces are permanent generators of aerosol particles (O'Dowd et al., 1997). Particles are also produced continuously in the atmosphere by condensation of semi-volatile organics (O'Dowd et al., 2002), and caused by photochemical reactions and gas $\rightarrow$ particle conversion (Vakeva et al., 1999; Holmes, 2007; Kumar et al., 2009). Volcanic eruptions (Amman \& Burtcher, 1990), forest fires (Makkonen et al., 2010) and dust storms (Schwikowski et al., 1995) are, temporally, very strong sources, but mostly local and of short duration.

Particulates are emitted from a number of various human activities (Baltensperger \& Nyeki, 1998; Kumar et al., 2010b). They are released at huge amounts through the chimneys of thermal power plants burning fossil fuel or biomass, incinerators, mineral mining and milling facilities and some others. In urban areas an important or even major particle source is traffic (Shi et al., 2001; Han et al., 2005; Agus et al., 2007; Young \& Keeler, 2007; Busek \& Adachi, 2008; Morawska et al., 2008; Kumar et al., 2010b). While particles emitted by vehicles using conventional and bio fuel are mostly smaller than $150 \mathrm{~nm}$, debris generated by the tyre-road interaction fall into the $2.5-10 \mu \mathrm{m}$ range. Nanoparticles are also produced intentionally (Kumar et al., 2010a) to be used as constituents in electronics, medicines, pharmaceuticals, cosmetics, paints and a variety of other consumer products. Nanotechnology is increasing fast and so is the possibility for the nanoparticles to appear in air of workplaces and to be released into the outdoor atmosphere and enter the living environment (Mackay \& Henry, 2009).

Apart from size, aerosol particles also differ markedly in their shape, structure and chemical composition, which is beyond the scope of this paper.

When breathing air, aerosol particulates are deposited partly on the walls of the respiratory tract. Mathematical simulations have shown that their deposition depends strongly on the particle size (Hofmann \& Koblinger, 1990; Alföldy et al., 2009). Thus, for instance (Oberdörster et al., 2005), about $90 \%$ of the inhaled $1 \mathrm{~nm}$ particles are deposited in the nasopharyngeal region and the rest, in the tracheobronchial region with no deposition in the alveolar region. $5 \mathrm{~nm}$ particles are almost equally deposited in all three regions. On the other hand, half of the $20 \mathrm{~nm}$ particles are deposited in the alveolar region and the remaining half in the other two regions equally. Physical translocation and clearance in the respiratory tract are also size-dependent. Aerosol particles enter the body also by ingestion and absorption 
by skin. This uptake is more effective for smaller particles than for larger ones, nonetheless minor compared with inhalation. Because the ratio of the numbers of surface to bulk atoms increases exponentially with reducing size, smaller particles are expected to be chemically and biochemically more reactive, and thus potentially more toxic, than larger ones (Oberdörster et al., 2005). It has been recognised that nanoparticles cause oxidation stress, pulmonary inflammation and cardiovascular events, although the mechanisms of these detrimental effects are not entirely understood (Nowack \& Bucheli, 2001; Oberdörster et al., 2005; Nel et al., 2006; Kumar et al., 2010b).

\subsection{Radioactive aerosols - radon short-lived decay products}

Atoms of several radionuclides attach to the atmospheric particles which thus appear as radioactive aerosols (Schery, 2001; Papastefanou, 2008). They are of different origin and may be classified as follows (Papastefanou, 2008): (i) cosmogenic: ${ }^{7} \mathrm{Be},{ }^{22} \mathrm{Na},{ }^{32} \mathrm{P}$ and ${ }^{35} \mathrm{~S}$; (ii) radon and thoron short-lived decay products; (iii) fission products: ${ }^{89} \mathrm{Sr},{ }^{90} \mathrm{Sr},{ }^{103} \mathrm{Ru},{ }^{131} \mathrm{I},{ }^{132} \mathrm{Te},{ }^{137} \mathrm{Cs}$ and ${ }^{140} \mathrm{Ba}$; (iv) originated from high-energy accelerators: ${ }^{7} \mathrm{Be},{ }^{22} \mathrm{Na},{ }^{24} \mathrm{Na}$ and ${ }^{52 \mathrm{Mn}}$; (v) plutonium isotopes from nuclear weapons testing and reactor accidents; and (vi) mine particulate matter containing radionuclides of the uranium, thorium and actinium radioactive decay chains. We shall focus here on radon short-lived decay products.

There are three primordial radioactive decay chains in the earth crust (Nero, 1988): the thorium chain starting with ${ }^{232} \mathrm{Th}$, the uranium chain starting with ${ }^{238} \mathrm{U}$, and the actinium chain starting with ${ }^{235} \mathrm{U}$. In each chain, radioactive transformation of radium results in formation of radon, the only gas in the entire decay chains. Thus, ${ }^{220} \mathrm{Rn}$ (thoron, half-life $t_{1 / 2}$ $=55.6 \mathrm{~s}$ ), ${ }^{222} \mathrm{Rn}$ (radon, 3.82 days) and ${ }^{219} \mathrm{Rn}$ (actinon, $3.9 \mathrm{~s}$ ) radon isotopes, respectively, are created. Only a fraction of radon atoms succeed in leaving the mineral grain due to their recoil energy, thus entering the void space. From there, radon travels through the medium either by diffusion or, more effectively and to longer distances, carried by gas or water (Etiope \& Martinelli, 2002). On its way, it accumulates in underground rooms (mines, karst caves, fissures, basements) and eventually enters the atmosphere, and appears in the air of living and working environments. We will deal here with ${ }^{222} \mathrm{Rn}$ (hereafter called radon, Rn) which, usually, only appears at significant levels in the environmental air because of its relatively long half-life, as compared with the half-life of ${ }^{220} \mathrm{Rn}$ and especially that of ${ }^{219} \mathrm{Rn}$.

Radon a-transformation is followed by a radioactive chain of its short-lived decay products $(\mathrm{RnDP}):{ }^{218 \mathrm{Po}}(\mathrm{a}, 3.05 \mathrm{~min}) \rightarrow{ }^{214} \mathrm{~Pb}(\beta, 26.8 \mathrm{~min}) \rightarrow{ }^{214} \mathrm{Bi}(\beta, 19.7 \mathrm{~min}) \rightarrow{ }^{214} \mathrm{Po}(\mathrm{a}, 164 \mu \mathrm{s})$ (Nero, 1988). Initially, they appear mostly as positive ions (Chu \& Hopke, 1988; Porstendörfer \& Reineking, 1992; Hopke, 1996) which react with molecules of trace gases and vapours (mostly water) in air, are partially oxidized and form small charged clusters. They also get neutralized (Goldstein \& Hopke, 1985; Porstendörfer \& Reineking, 1992; Hopke, 1996) by (i) recombination with ion pairs produced by $\alpha, \beta$ and $\gamma$ emissions and recoil atoms during radioactive transformations of airborne radionuclides, as well as by background $\gamma$ and cosmic rays, (ii) electron scavenging by $\mathrm{OH}$ radicals formed by radiolysis of water molecules, and (iii) charge transfer from molecules of lower ionisation potential. The state of ${ }^{218} \mathrm{Po}$ and ${ }^{218} \mathrm{PoO}_{2}$ at the moment of its a-transformation is decisive because it determines the initial characteristics and behaviour of the subsequent members in the chain. For ${ }^{218} \mathrm{Po}$ clusters in $50 \%$ humid air at an ionisation rate of $3.2 \mathrm{pC} \mathrm{kg}^{-1} \mathrm{~s}^{-1}\left(45 \mu \mathrm{R} \mathrm{h} \mathrm{h}^{-1}\right)$, the rates of the above three processes of neutralisation are $0.07 \times 10^{-2} \mathrm{~s}^{-1}, 1.07 \times 10^{-2} \mathrm{~s}^{-1}$ and $0.4 \times 10^{-2} \mathrm{~s}^{-1}$, respectively, and more than half of the clusters are neutral (Dankelmann et al., 
2001). These processes are accompanied and followed by attachment of clusters (Hopke, 1996; Dankelmann et al., 2001; Schery, 2001; Pagelkopf \& Porstendörfer, 2003; Papastefanou, 2008), both charged and already neutralised, to the background atmospheric aerosol particles. Because of the recoil energy gained during a-transformation of the attached parent atoms, a considerable proportion of the RnDP atoms desorbs from the aerosol particles (Mercer, 1976; Porstendörfer, 1984), the phenomenon being more pronounced for smaller aerosol particles (Tu et al., 1994).

The total concentration of RnDP in air is reported as the equivalent equilibrium activity concentration $\left(C_{\mathrm{RnDP}}^{\mathrm{A}}, \mathrm{Bq} \mathrm{\textrm {m } ^ { - 3 }}\right)$ expressed as (Nero, 1988):

$$
C_{\mathrm{RnDP}}^{\mathrm{A}}=0.1065 C_{218 \mathrm{Po}}^{\mathrm{A}}+0.515 C_{214 \mathrm{~Pb}}^{\mathrm{A}}+0.379 C_{214 \mathrm{Bi}}^{\mathrm{A}},
$$

where $\mathrm{C}^{\mathrm{A}}\left(\mathrm{Bq} \mathrm{m}^{-3}\right)$ stands for the individual activity concentrations of ${ }^{218} \mathrm{Po},{ }^{214} \mathrm{~Pb}$ and ${ }^{214} \mathrm{Bi}$. Because of its short life time, ${ }^{214} \mathrm{Po}$ activity is equal to the activity of ${ }^{218} \mathrm{Bi}$ and is therefore already included in the last term of Eq. 3. Due to air movement and deposition of RnDP onto surfaces, individual activity concentrations of RnDP are always lower than that of radon $\left(C_{\mathrm{Rn}}^{\mathrm{A}}\right)$ and secular equilibrium between radon and $\mathrm{RnDP}$ is never reached in the ambient air, and the degree of equilibrium is defined as $F=C_{\mathrm{RnDP}}^{\mathrm{A}} / C_{\mathrm{Rn}}^{\mathrm{A}}$.

On the world average, RnDP contribute about half to the effective dose (radon contribution is minor) a member of the general public receives from all natural radioactivity (United Nations Scientific Committee on the Effects of Atomic Radiation [UNSCEAR], 2000, thereafter UNSCEAR, 2000), and are a major cause of lung cancer, second only to cigarette smoking (Darby et al., 2005). For this reason, their levels in living and working environments are of great social concern and scientific challenge.

In contrast to general aerosols, the health detrimental effects of radioactive aerosols have been known for a long time and their dosimetry well elaborated. For general purposes of radiation protection, the International Commission of Radiological Protection in its Publication 65 recommends for radon dosimetry a dose conversion factor $\left(D_{\mathrm{CFE}}\right)$ of $4 \mathrm{mSv}$ $\mathrm{WLM}^{-1}$ at home and $5 \mathrm{mSv} \mathrm{WLM}^{-1}$ at the workplace (International Commission on Radiological Protection [ICRP], 1994, thereafter ICRP, 1994), as the values deduced from epidemiologic studies. Above, 1 WLM (working-level-month) is the exposure gained by 170 hour breathing air in which the potential a-energy concentration of $\operatorname{RnDP}\left(E_{\mathrm{aRnDP}}\right)$ is $1.3 \times 10^{8}$ $\mathrm{MeV} \mathrm{m}{ }^{-3}$. $E_{\mathrm{aRnDP}}\left(\mathrm{MeV} \mathrm{m}^{-3}\right)$ is expressed through the activity concentrations $\left(\mathrm{C}^{\mathrm{A}}, \mathrm{Bq} \mathrm{m}^{-3}\right)$ of ${ }^{218} \mathrm{Po},{ }^{214} \mathrm{~Pb}$ and ${ }^{214} \mathrm{Bi}$, as (Nero, 1988):

$$
E_{\mathrm{aRnDP}}=3690 C_{218 \mathrm{Po}}^{\mathrm{A}}+17830 C_{214 \mathrm{~Pb}}^{\mathrm{A}}+113120 C_{214 \mathrm{Bi}}^{\mathrm{A}} .
$$

On the other hand, Birchall and James (Birchall \& James, 1994; Marsh et al., 2002) elaborated the dosimetric approach of calculating the dose conversion factor $\left(D_{\mathrm{CFD}}\right)$ which is used mainly for research purposes. They also showed that the parameter mostly affecting $D_{\mathrm{CFD}}$ is the fraction (fun) of the unattached RnDP, defined as (Nero, 1988):

$$
f^{\mathrm{un}}=\frac{C_{\mathrm{RnDP}}^{\mathrm{Aun}}}{C_{\mathrm{RnDP}}^{\mathrm{A}}}
$$

where $C_{\mathrm{RnDP}}^{\mathrm{Aun}}$ is the equivalent equilibrium concentration of the unattached RnDP, obtained if activity concentrations of only the unattached ${ }^{218} \mathrm{Po},{ }^{214} \mathrm{~Pb}$ and ${ }^{214} \mathrm{Bi}$ are taken into Eq. 3. Further, they expressed $D_{\mathrm{CFD}}$ based on fun with an empirical formula: 


$$
D_{\text {CFD }}=11.35+43 \text { fun. }
$$

In addition, Porstendörfer (1996) proposed relationships between $D_{\text {CFD }}$ and fun for $0.8 \mathrm{~nm}$ RnDP:

$$
D_{\mathrm{CFD}}=101 \text { fun }+6.7(1-\text { fun }) \text { for nasal breathing }
$$

and

$$
D_{\mathrm{CFD}}=23 \text { fun }+6.2(1-\text { fun }) \text { for mouth breathing. }
$$

Because fun is the key factor in radon dosimetry models it is of great interest to know the parameters influencing its values and time variation in various environments.

\subsection{Size distribution of radon short-lived decay products}

For RnDP, as for other radioactive aerosols (Schery, 2001; Papastefanou, 2008), the activity size distribution $P_{\mathrm{L}}^{\mathrm{A}}(d)$ is most often reported, rather than the number size distribution $P_{\mathrm{L}}^{\mathrm{N}}(d)$ (Eq. 2); it is expressed as:

$$
P_{\mathrm{L}}^{\mathrm{A}}(d)=-\frac{\mathrm{d} C^{\mathrm{A}}}{\mathrm{d}(\ln d)} .
$$

The two distributions differ because the attachment coefficient $\beta(d)$ of RnDP to aerosol particles is a function of size; the relationship between them is (Porstendörfer, 1996; Porstendörfer et al., 2000):

$$
P_{\mathrm{L}}^{\mathrm{A}}(d)=\frac{C^{\mathrm{A}}}{X} \beta(d) P_{\mathrm{L}}^{\mathrm{N}}(d)
$$

Here, $X$ is the attachment rate and expresses the adsorption velocity of RnDP to aerosol particles at their number concentration $C^{N}$, and $\beta(d)$ is determined by the diffusion coefficient, velocity and mean free path of RnDP. Under different environmental conditions, values of $X$ were found to range from $7 \mathrm{~h}^{-1}$ to $1660 \mathrm{~h}^{-1}$ (Reineking et al., 1985; Tu et al., 1991) and those of $\beta(d)$, from $0.2 \times 10^{-3} \mathrm{~cm}^{3} \mathrm{~h}^{-1}$ to $14.1 \times 10^{-3} \mathrm{~cm}^{3} \mathrm{~h}^{-1}$ (Reineking et al., 1985; Porstendörfer, 1984; Tokonami, 2000).

According to a review by Porstendörfer \& Reineking, (1992), the activity median diameter (AMD) of the RnDP clusters falls in the range of $0.9 \mathrm{~nm}$ to $30 \mathrm{~nm}$, while the activity median aerodynamic diameter (AMAD) of the aerosol particles carrying RnDP attached, falls in the range of $50 \mathrm{~nm}$ to $500 \mathrm{~nm}$. In a radon chamber containing carrier aerosol, AMD values of $0.82,0.79,1.7$ and $0.82 \mathrm{~nm}$ were obtained for unattached ${ }^{218} \mathrm{Po},{ }^{214} \mathrm{~Pb},{ }^{214} \mathrm{Bi}$ and ${ }^{214} \mathrm{Po}$, respectively (Fukutsu et al., 2004). The border between unattached and attached is not fixed. Thus, for indoor air, RnDP associated to particles smaller than $20 \mathrm{~nm}$, grouped around $5 \mathrm{~nm}$ (Tu et al., 1991), and particles in the $0.5-1.5 \mathrm{~nm}$ size range may be considered as unattached RnDP (Hopke et al., 1992). Measurements in indoor air also showed that within the unattached region of $<10 \mathrm{~nm}$, two (with AMD of 0.8 and $4.2 \mathrm{~nm}$ ) or even three activity distribution peaks (0.6, 0.85 and $1.25 \mathrm{~nm}$ ) may appear (Porstendörfer, 1996; Porstendörfer, 2001). In addition, RnDP appeared in the nucleation mode (attached to particles of 14-40 $\mathrm{nm})$, the accumulation mode (210-310 nm), and the coarse mode (3000-5000 nm) (Porstendörfer, 2001). In an intercomparison experiment carried out in a test chamber, the 
AMD values of the unattached RnDP were found in the range from 0.53 to $1.76 \mathrm{~nm}$, followed by a gap until about $50 \mathrm{~nm}$ when the attached RnDP appeared (Cheng et al., 2000). As reviewed by Porstendörfer \& Reineking, (1992), fun differs substantially from place to place and, depending on the environmental conditions, its value range from 0.006 to 0.83 . Generally, it is inversely proportional to the number concentration of general aerosol particles (Butterweck et al., 1992; Cheng et al., 1997), the relationship being approximated by (Porstendörfer, 1996):

$$
f^{\text {un }}=\frac{400}{C_{\text {gen }}^{\mathrm{N}} / \mathrm{cm}^{-3}} .
$$

Thus, fun is very low in mines with high aerosol concentrations (Butterweck et al., 1992) and high in karst caves with very clean air (Butterweck et al., 1992; Cheng et al., 1997; Sainz et al., 2007; Thinová \& Burian, 2008).

Elevated fun values have been also observed in the Postojna Cave (Butterweck et al., 1992; Vaupotič, 2008b). Because the behaviour of RnDP aerosols, including fun values, is determined by the characteristics of general aerosols, measurements of the number concentration and size distribution of general aerosol particles in the 10-1100 $\mathrm{nm}$ size range were recently introduced in the cave (Iskra et al., 2010). This kind of measurements has been also extended to selected indoor and outdoor places. In the present paper, measurements in the Postojna Cave and in a dwelling in a suburban area are described, and results are presented and commented on.

\section{Experimental}

\subsection{Measuring techniques \\ 2.1.1 Radon decay products}

Individual activity concentrations $\left(\mathrm{CA}, \mathrm{Bq} \mathrm{m}^{-3}\right)$ of ${ }^{222} \mathrm{Rn},{ }^{218} \mathrm{Po},{ }^{214} \mathrm{~Pb},{ }^{214} \mathrm{Bi} /{ }^{214} \mathrm{Po}$ have been measured using the EQF3020-2 device (Sarad, Germany). Air is pumped for 6 minutes at a flow rate of $2.4 \mathrm{dm}^{3} \mathrm{~min}^{-1}$ over a metal mesh grid on which aerosols smaller than $5 \mathrm{~nm}$ (considered as unattached RnDP) are separated from those above this size (considered as attached RnDP). The two fractions are deposited electrostatically on two separate $150 \mathrm{~mm}^{2}$ semiconductor detectors. Gross alpha activity is measured during three consecutive intervals within 110 minutes after the end of pumping and, applying the Markov method (Markov, 1962), individual activity concentrations of ${ }^{218} \mathrm{Po},{ }^{214} \mathrm{~Pb}$ and ${ }^{214} \mathrm{Bi}$ in the unattached and attached fractions are obtained. The device also gives radon activity concentration $\left(C_{R n}^{A}\right)$, equivalent equilibrium activity concentration of $\operatorname{RnDP}\left(C_{\mathrm{RnDP}}^{\mathrm{A}}\right)$, equilibrium factor between $\operatorname{Rn}$ and $\operatorname{RnDP}(F)$, fraction of the unattached RnDP (fun), potential a-energy concentration of $\operatorname{RnDP}\left(E_{\mathrm{aRnDP}}\right)$, as well as air temperature and humidity.

In order to facilitate comparison of number concentrations of general aerosols and RnDP aerosols, the activity concentrations $\left(C^{A}\right)$ of radionuclides are converted into their number concentrations $\left(\mathrm{CN}^{\mathrm{N}}\right)$, by applying the radioactivity law equation: $C^{A}=\lambda \times C^{\mathrm{N}}$, with $\lambda=\ln 2$ / $t_{1 / 2}$. The obtained number concentrations of ${ }^{218} \mathrm{Po},{ }^{214} \mathrm{~Pb}$ and ${ }^{214} \mathrm{Bi}$ atoms $\left(\mathrm{cm}^{-3}\right)$ are denoted by $C_{218 \mathrm{Po}}^{\mathrm{Nun}}, C_{214 \mathrm{~Pb}}^{\mathrm{Nun}}$ and $C_{214 \mathrm{Bi}}^{\mathrm{Nun}}$, for the unattached, and $C_{218 \mathrm{Po}}^{\mathrm{Nat}}, C_{214 \mathrm{~Pb}}^{\mathrm{Natt}}$ and $C_{214 \mathrm{Bi}}^{\mathrm{Natt}}$, for the attached RnDP. 


\subsubsection{General aerosols}

Number concentration and size distribution of general aerosol particles have been measured with a Grimm Aerosol SMPS+C instrument, Series 5.400. A long Vienna DMA unit was used for 10-1100 $\mathrm{nm}$ and a medium DMA unit, for 5-350 $\mathrm{nm}$ size range. The DMA unit separates charged particles into 44 channels, based on their electrical mobility which depends on the particle size and electrical charge: the smaller the particle and the higher its electrical charge the higher is its mobility. Particles enter the CPC unit containing a heater saturator in which alcohol vapour molecules condense onto the entering particles, thus causing them to grow into droplets. The droplets are then detected with a laser beam (DLS detection) and counted. The frequency of measurement is one in seven minutes for the long, and one in four minutes for the medium DMA unit. The instrument gives the total number concentration $C_{\text {gen }}^{\mathrm{N}}($ tot), geometric mean of particle diameter $\left(\mathrm{GM}_{\mathrm{pd}}\right)$, and size distribution $\mathrm{d} C_{\text {gen }}^{\mathrm{N}}(d) / \mathrm{d} \ln d$, where $d$ is the electrical mobility equivalent particle diameter.

\subsection{Site description}

Two experimental sites were selected: the Postojna Cave and a dwelling in the suburban area.

\subsubsection{Postojna Cave}

The Postojna Cave is the largest show cave in Slovenia. Like the majority of karst caves, it is only naturally ventilated. Its air temperature is practically constant around $9{ }^{\circ} \mathrm{C}$ all the year round and relative air humidity is close to $100 \%$. It is a practically horizontal cave. The air flow differs considerably in summer and winter. In winter, when the cave temperature is higher than outside, cave air is released from the cave into the outdoor atmosphere due to the air draught caused by the 'chimney effect' (Hakl et al., 1997; Kertész et al., 1999), thus allowing fresh and cold outdoor air to enter the cave through low lying openings. This effect is not operative in summer, when the outside temperature is higher than in the cave, and air draught is minimal or reversed. The air speed is low, never exceeding $1.5 \mathrm{~m} \mathrm{~s}^{-1}$ along the main entrance corridor and being much less or zero in other parts. As a result of different natural ventilation regimes, the cave interior, at least along the main air paths, is less wet in winter than in summer.

The cave is open for visitors every day from $10 \mathrm{~h}$ to $16 \mathrm{~h}$ in winter and from $9 \mathrm{~h}$ to $18 \mathrm{~h}$ in other seasons. The daily number of visitors is around 3500 in summer and from fifty to several hundred in winter, totalling about half a million a year. Visitors ride an electric train for the first $2 \mathrm{~km}$ from the entrance to the train stop in the cave, walk $1.8 \mathrm{~km}$ on an 8 -shaped route and return back to the train in about an hour and a half. The lowest point, our study site, is in the middle of the walking route. The walking path is paved with a special concrete containing silica sand to prevent slippery steps when wet.

The major source of particulate matter in the cave air is the inflow of fresh outside air in winter time. Deposition of dust is observed on the surfaces in the main corridor all the way from the entrance to the train stop, but not further. Another source is the railway. Particles originate from rusting of iron parts, grinding of sand, and rotting and damages of wooden sleepers. The particles are lifted and resuspended by the air draught caused by the train running at a speed of $1.6 \mathrm{~m} \mathrm{~s}^{-1}$ through the narrow corridors and galleries. Also human activity, both visits and maintenance work at the cave infrastructure, is a potential source. 
In the cave, radon and RnDP have been monitored systematically for years in order to estimate radiation doses for the personnel and to keep them below an acceptably low level (Vaupotič, et al., 2001). In addition to elevated radon levels, as found in many caves worldwide (Hakl et al., 1997; Cigna, 2005; Field, 2007; Vaupotič, 2010; Kávási et al., 2010), fun values are also high (Vaupotič, 2008b), as also in some other caves (Cheng et al., 1997; Sainz et al., 2007; Thinová \& Burian, 2008). They are considerably higher than in Slovenian kindergartens (Vaupotič, 2007), schools (Vaupotič \& Kobal, 2006) and wineries (Vaupotič, 2008a). Preliminary measurements showed (Butterweck et al., 1992) that the activity size distribution of RnDP was bimodal, with the unattached fraction in the range 1.3-6.0 $\mathrm{nm}$ and the attached, $119-289 \mathrm{~nm}$.

Previous radon measurements (Vaupotič, et al., 2001; Vaupotič, 2008b; Gregorič et al., 2011) pointed out that the difference in air temperature outside and in the cave played a dominant role in governing both diurnal and seasonal variations of the environmental conditions in the cave. Radon levels were lowest in winter when the cave temperature is higher than outdoors, because radon-rich air is released from the cave into the outdoor atmosphere and fresh outdoor air with low radon concentration is driven into the cave. This effect is not operative in summer, when the outdoor air temperature is higher than in the cave, and the resulting radon levels in the cave air are higher. As an example, at the lowest point the following average values in summer and in winter, respectively, were obtained in 1999 (Vaupotič, 2008b): $C_{\mathrm{Rn}}^{\mathrm{A}}: 4540 \pm 600 \mathrm{~Bq} \mathrm{~m}^{-3}$ and $2070 \pm 1160 \mathrm{~Bq} \mathrm{~m}^{-3}, \mathrm{C}_{\mathrm{RnDP}}^{\mathrm{A}}: 1580 \pm 280 \mathrm{~Bq} \mathrm{~m}^{-3}$ and $1130 \pm 530 \mathrm{~Bq} \mathrm{~m}^{-3}, F: 0.35 \pm 0.09$ and $0.58 \pm 0.11$, and fun: $0.60 \pm 0.16$ and $0.14 \pm 0.08$.

Several 5-10 day measurements were carried out with the EQF devices in summer 2009 and winter 2010 at the lowest point along the guided walking route in the cave. Within these periods, the SMPS $+C$ instrument with the long DMA unit was also used, but for several hours only during morning visits, because the instrument is not designed for practically 100 $\%$ air humidity and therefore its operation was minimized.

Bearing in mind that RnDP in the Postojna Cave are attached to aerosols larger than $100 \mathrm{~nm}$ (Butterweck et al., 1992), we selected $50 \mathrm{~nm}$ as the border between the unattached and attached RnDP. We were thus interested in concentrations of particles smaller than $50 \mathrm{~nm}$ $\left(C_{\text {gen }}^{\mathrm{N}}(\langle 50))\right.$ and larger than $50 \mathrm{~nm}$, as well as the fraction of the smaller ones, defined as $x_{\text {gen }}\left(\langle 50)=C_{\text {gen }}^{\mathrm{N}}\left(\langle 50) / C_{\text {gen }}^{\mathrm{N}}(\right.\right.$ tot $)$.

\subsubsection{Dwelling}

A farm in Zalog, a suburb of Ljubljana, was selected for our experiment. It comprised a residential house and several accompanying farm buildings. They were built in 1987 of concrete and brick. The family lives in the ground floor of the residential house, while the first floor is left unoccupied. One person lives temporarily in a small $20 \mathrm{~m}^{2}$ flat in the basement, its floor lying $1.2 \mathrm{~m}$ below the courtyard level. It consists of a kitchen, living room, bathroom and corridor. A door and a window of the kitchen look at the courtyard in front of the house, while the other door connects it to other rooms. Central heating using hot water radiators is based on burning wood. There is no air conditioning. The farm is situated at the end of a small farmers' village, at a distance of about $20 \mathrm{~m}$ from the Ljubljanica River and with the nearest neighbour about $50 \mathrm{~m}$ away. The village is surrounded by fields. Across the river at a distance of about $500 \mathrm{~m}$, the main railway Ljubljana - Zagreb runs along a hill covered by forest. The Ljubljana waste water purification plant is about $400 \mathrm{~m}$ out of the village and several small industrial plants are several kilometres away. 
Measurements were performed in the kitchen of the basement flat (Smerajec et al., 2010) in which a preliminary radon survey had shown elevated radon activity concentration, ranging from $600 \mathrm{~Bq} \mathrm{~m}^{-3}$ to $1000 \mathrm{~Bq} \mathrm{~m}^{-3}$, as compared with the national winter average of $121 \mathrm{~Bq} \mathrm{~m}^{-3}$ for a thousand dwellings (Humar et al., 1992). Both instruments were operated simultaneously from October 2010 to January 2011, covering temporal human activities, e. g., cooking, washing, opening window and door, etc. Here, the medium DMA unit was used. Because it is designed for $>5 \mathrm{~nm}$ sizes, the size distribution of the unattached RnDP could not be evaluated. Therefore the assumption (Tu et. al., 1991; Shimo \& Saito, 2000) was adopted that the attached RnDP in indoor air are associated with particles larger than 20 $\mathrm{nm}$. Thus, the fraction of the general aerosol particles related to the unattached RnDP was expressed by $x_{\text {gen }}\left(\langle 20)=C_{\text {gen }}^{\mathrm{N}}\left(\langle 20) / C_{\text {gen }}^{\mathrm{N}}(\right.\right.$ tot $)$.

\section{Results and discussion}

Results are presented separately for the Postojna Cave in summer and in winter, and for the dwelling.

\subsection{Postojna Cave}

\subsubsection{Summer results}

For one of the measurement carried out in summer, Fig. 1 shows the size distribution of general aerosols (a) before visits started and (b) during regular visits. Their geometric mean values $\left(\mathrm{GM}_{\mathrm{pd}}\right)$ of 26 and $31 \mathrm{~nm}$ did not differ significantly.

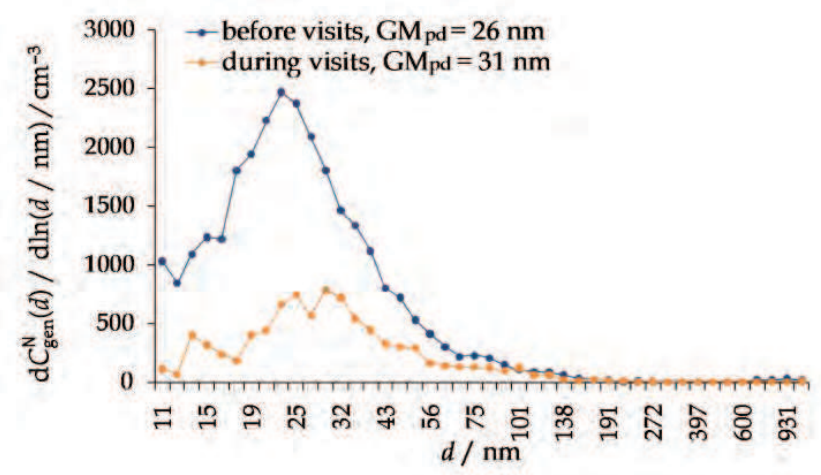

Fig. 1. Number size distribution $\left(\mathrm{d} C_{\text {gen }}^{\mathrm{N}}(d) / \mathrm{d} \ln (d / \mathrm{nm})\right)$ of general aerosol particles at the lowest point in the Postojna Cave in summer 2009: a) before visits started and b) during regular visits

The decrease in total number concentration $\left(C_{\text {gen }}^{\mathrm{N}}(\right.$ tot $)$ ) from $2700 \mathrm{~cm}^{-3}$ to $700 \mathrm{~cm}^{-3}$ is mainly due to the smaller particles while concentrations of larger ones remained practically constant during our measurement (Fig. 2). As seen in Fig. 3, the concentration of the $>50 \mathrm{~nm}$ particles remained practically constant during visits, while that of $<50 \mathrm{~nm}$ ones, contributing $80-90 \%$ of the total concentration, is steadily decreasing. This is presumably because the smaller particles are preferentially deposited on the cave surfaces (Holub et al., 1988; 
Porstendörfer, 1984; Morawska \& Jamriska, 1996; Papastefanou, 2008), and caught by cloths (Balcázar et al., 1999) and taken up by the lungs (Hofmann \& Koblinger, 1990; Alföldy et al., 2009) of visitors walking, and thus enhancing air turbulence (Vanmarcke et al., 1991), through the narrow corridor at the lowest point of a cross section of less than $20 \mathrm{~m}^{2}$.

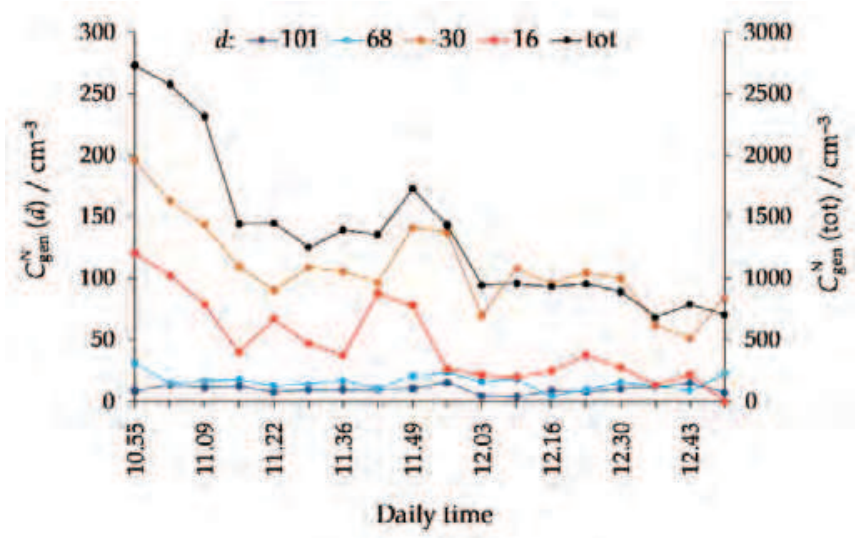

Fig. 2. Time run of the total number concentration of general aerosol particles $\left(C_{\text {gen }}^{\mathrm{N}}(\right.$ tot $\left.)\right)$ and number concentrations of particle of various sizes $\left(C_{\mathrm{gen}}^{\mathrm{N}}(d)\right)$ at the lowest point in the Postojna Cave in summer 2009

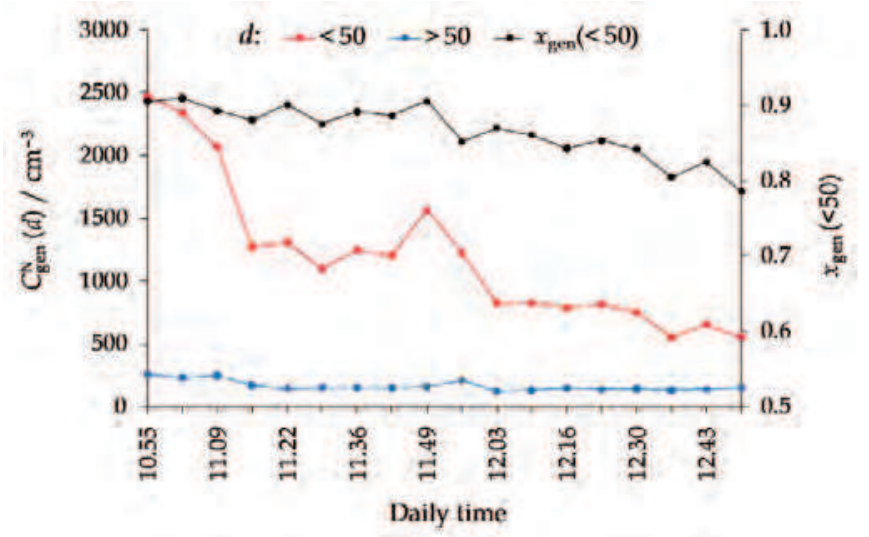

Fig. 3. Time run of number concentrations of general aerosol particles smaller $\left(C_{\text {gen }}^{\mathrm{N}}(\langle 50))\right.$ and larger $\left.\left(C_{\text {gen }}^{\mathrm{N}}(\rangle 50\right)\right)$ than $50 \mathrm{~nm}$, and the fraction of the smaller particles $\left(x_{\text {gen }}(\langle 50))\right.$ at the lowest point in the Postojna Cave in summer 2009

Figure 4a shows the radon activity concentration $\left(C_{R n}^{A}\right)$ and equilibrium factor $(F)$, and Fig. $4 \mathrm{~b}$, the equivalent equilibrium activity concentration of $\operatorname{RnDP}\left(C_{\mathrm{RnDP}}^{\mathrm{A}}\right)$ and fraction of unattached RnDP (fun). As expected from previous monitoring in summer (Vaupotič, 2008b), $C_{\mathrm{Rn}}^{\mathrm{A}}$ and fun are high and $F$ is low. During the period when the general aerosols were also monitored, fun values were around 0.75 (Fig. 4b), resulting in a $D_{\text {CFD }}$ value of $43.6 \mathrm{mSv}$ 
$\mathrm{WLM}^{-1}$ according to Eq. 6 or $77.4 \mathrm{mSv}^{\mathrm{WLM}}{ }^{-1}$ according to Eq. 7 (as compared with $D_{\mathrm{CFE}}=5$ $\mathrm{mSv} \mathrm{WLM}^{-1}$ for workplaces). For this period, Fig. 5a shows the individual number concentrations of the unattached, and Fig. 5b, of the attached RnDP atoms. The measurement frequency of the EQF device is much lower (once in two hours) than that of the Grimm device (once in seven minutes) and therefore time variations of the parameters measured with the two cannot be adequately compared. The number concentration of the unattached ${ }^{218} \mathrm{Po}$ atoms is lowest because of the shorter half-life in comparison to other RnDP. On the other hand, the ratio of the numbers of its unattached and attached atoms was initially 26, far larger than those of ${ }^{214} \mathrm{~Pb}$ and ${ }^{214} \mathrm{Bi}$, being 5.2 and 0.65 , respectively. There are several reasons for this high fraction for ${ }^{218 P o . ~ B e c a u s e ~ o f ~ i t s ~ s h o r t ~ h a l f-l i f e ~ i n ~ c o m p a r i s o n ~}$ with other RnDP, it has less time available to become attached to atmospheric particles. The second reason is based on the diffusion coefficients. They are in the ranges of (0.024-0.039) $\mathrm{cm}^{2} \mathrm{~s}^{-1}$ for the charged RnDP species and $(0.068-0.085) \mathrm{cm}^{2} \mathrm{~s}^{-1}$ for the neutral species (Porstendörfer \& Mercer, 1979; Tokonami, 1999). At the radon activity concentration of about $5500 \mathrm{~Bq} \mathrm{~m}^{-3}$, as in our case (Fig. 4 a), $13 \%$ of ${ }^{218}$ Po species are estimated to be charged (Chu \& Hopke, 1988). Because of their lower mobility, attachment of the charged species is hindered. This effect cannot be estimated for ${ }^{214} \mathrm{~Pb}$ and ${ }^{214} \mathrm{Bi}$, because data are not available. At the end of our measurement, the ratios of the numbers of unattached and attached ${ }^{218} \mathrm{Po}$, ${ }^{214} \mathrm{~Pb}$ and ${ }^{214} \mathrm{Bi}$ atoms were 6.6, 5.0 and 0.86 , respectively. The value for $218 \mathrm{Po}$ decreased drastically, concomitantly with lowering concentration of the $<50 \mathrm{~nm}$ particles, while the other two did not change significantly.

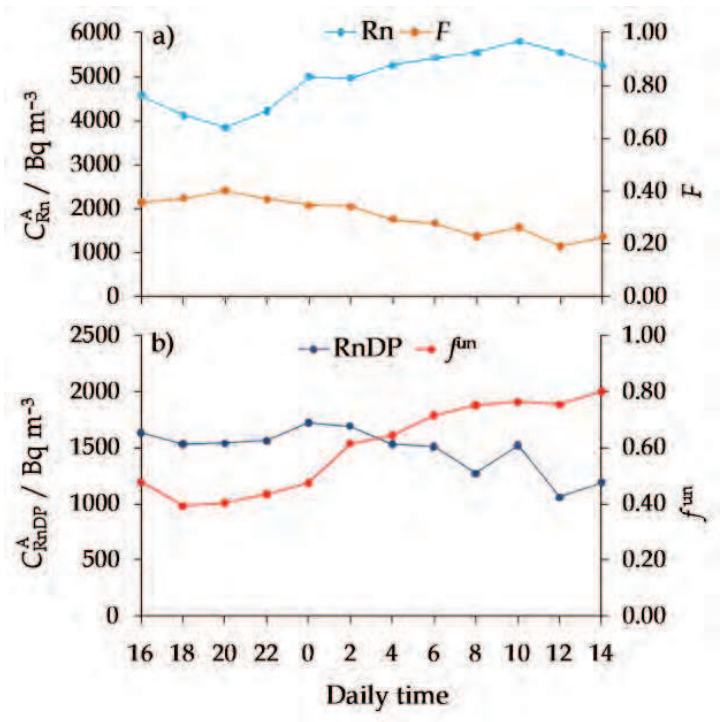

Fig. 4. Results of a continuous radon measurement at the lowest point in the Postojna Cave in summer 2009: a) radon activity concentration $\left(C_{R n}^{A}\right)$ and equilibrium factor between radon and its decay products $(F)$, and $b$ ) equivalent equilibrium activity concentration of radon decay products $\left(C_{\mathrm{RnDP}}^{\mathrm{A}}\right)$ and fraction of unattached decay products (fun) 


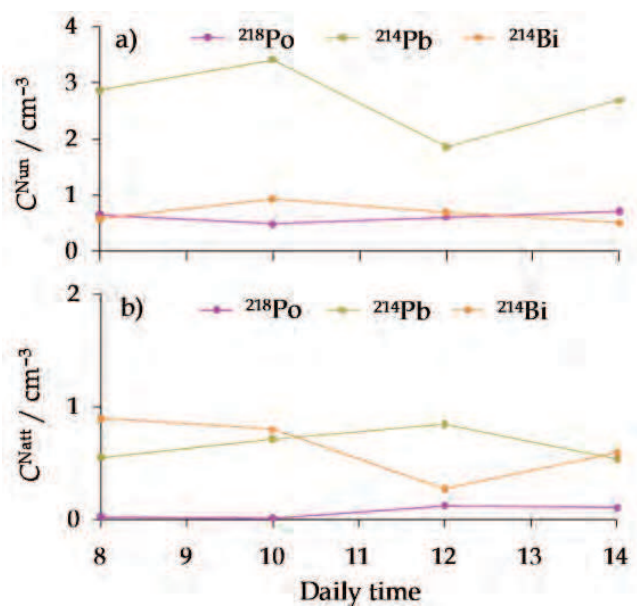

Fig. 5. Number concentrations of ${ }^{218} \mathrm{Po},{ }^{214} \mathrm{~Pb}$ and ${ }^{214} \mathrm{Bi}$ atoms for the period in Fig. 4 when general aerosols were also monitored: $\mathrm{a})$ in the unattached form $\left(C_{214 \mathrm{Po}}^{\mathrm{Nun}}, C_{214 \mathrm{~Pb}}^{\mathrm{Nun}}\right.$ and $\left.C_{214 \mathrm{Bi}}^{\mathrm{Nun}}\right)$, and $b)$ attached form $\left(C_{214 \mathrm{Po}}^{\mathrm{Natt}}, C_{214 \mathrm{~Pb}}^{\mathrm{Natt}}\right.$ and $\left.C_{214 \mathrm{Bi}}^{\mathrm{Natt}}\right)$

Number concentrations of RnDP atoms are several orders of magnitude lower than the total number concentration of general aerosols (Fig. 2). Therefore, we do not believe that the reason for high fun values in the cave air is only a low concentration of general aerosols (Butterweck et al., 1992; Cheng et al., 1997; Meisenberg \& Tschiersch, 2009), but rather the dominating contribution of their $<50 \mathrm{~nm}$ fraction to which the unattached RnDP are associated. This assumption is further supported by the data in Fig. 6: in a volume unit, the total surface area of all $<50 \mathrm{~nm}$ particles, to which the unattached RnDP are related, is two to eight times lower than that of the larger particles but, on the other hand, the number of the

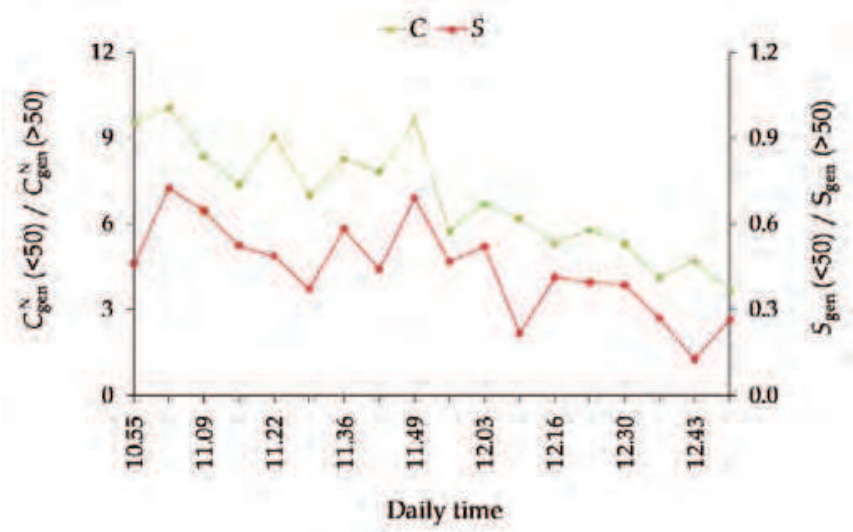

Fig. 6. Ratio of the number concentration of general aerosol particles smaller than $50 \mathrm{~nm}$ $\left(C_{\text {gen }}^{\mathrm{N}}(\langle 50))\right.$ to that of larger ones $\left.\left(C_{\text {gen }}^{\mathrm{N}}(\rangle 50\right)\right)$, and ratio of the total surface area of all particles smaller than $50 \mathrm{~nm}\left(S_{\text {gen }}(\langle 50))\right.$ to that of all particles larger than $\left.50 \mathrm{~nm}\left(S_{\text {gen }}(\rangle 50\right)\right)$ in a volume unit for the measurement in summer 2009 
smaller ones is four to ten times higher than that of the larger ones. Thus, the probability of $\mathrm{RnDP}$ atoms being associated with smaller particle-clusters is favoured, even without the fact that the ratio of the number of surface atoms, as adsorption sites, to the total number of atoms is substantially greater on the smaller particles than on the larger ones (Oberdörster et al., 2005).

\subsubsection{Winter results}

The number size distribution of general aerosols, (a) before visits started and (b) during regular visits, was measured in winter (Fig. 7). The related $\mathrm{GM}_{\mathrm{pd}}$ values, i. e., $110 \mathrm{~nm}$ and 113 $\mathrm{nm}$, respectively, are substantially higher than in summer (Fig. 1). They are similar to those in the Bozokov Dolomite Cave in the Czech Republic (Thinová et al., 2005; Rovenská et al., 2008) but smaller than in a limestone cave in Australia (Solomon et al., 1992). The total concentration of general aerosols and concentrations of aerosol particles of various diameters is displayed in Fig. 8. In contrast to the situation in summer (Fig. 2), the total concentration gradually increased during visits, from $2000 \mathrm{~cm}^{-3}$ to $2800 \mathrm{~cm}^{-3}$ and is similar to the initial value in summer of $\left(2700 \mathrm{~cm}^{-3}\right)$, but was much higher than during visits in summer $\left(700 \mathrm{~cm}^{-3}\right)$. Higher concentration in winter cannot be understood as a result of higher air ionisation due to the radioactivity present (Pashenko \& Dublyansky, 1997), because both $C_{\mathrm{Rn}}^{\mathrm{A}}$ and $C_{\mathrm{RnDP}}^{\mathrm{A}}$ are lower, and thus ionization is also lower in winter than in summer. Because the number size distribution in winter is similar to that observed in outdoor air in a suburban area $\left(C_{\text {gen }}^{\mathrm{N}}(\right.$ tot $)=$ $7155 \mathrm{~cm}^{-3}, \mathrm{GM}_{\mathrm{pd}}=110 \mathrm{~nm}$ ) (Smerajec et al., 2010), although with lower total concentration, these high values are most probably reached as a result of the aerosol particles introduced in winter by the inflow of outside air. This inflow is assumed to decrease slightly during morning hours due to an increase in the outside air temperature, and thus decreased difference between temperatures in the cave and outside. Therefore, the increase in the total aerosol concentration in morning hours is not caused by the inflow of outside air but from the particles resuspended and brought by visitors walking on the paved path, which is less wet in winter than in summer. As a result of larger particles dominating in winter, $x_{\text {gen }}(\langle 50)$ values are substantially lower in winter (Fig. 9) than in summer (Fig. 3).

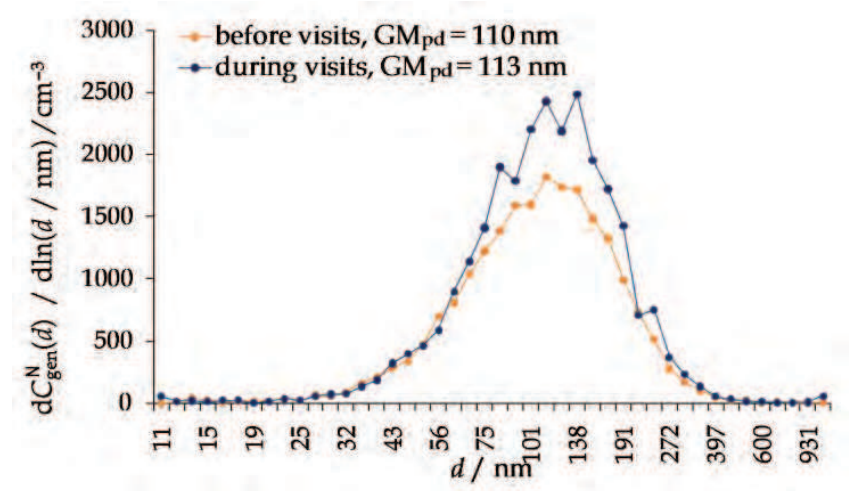

Fig. 7. Number size distribution $\left(\mathrm{d} C_{\text {gen }}^{\mathrm{N}}(d) / \mathrm{d} \ln (d / \mathrm{nm})\right)$ of general aerosol particles at the lowest point in the Postojna Cave in winter 2010: a) before visits started and b) during regular visits 


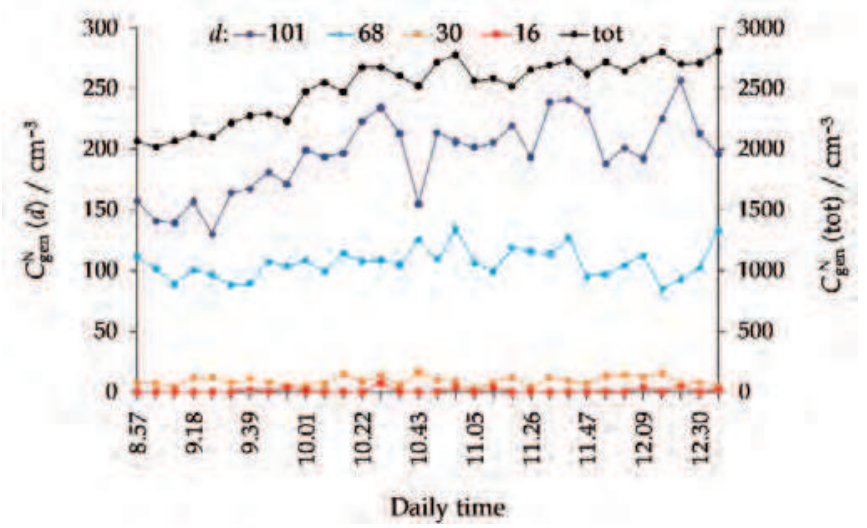

Fig. 8. Time run of the total number concentration of general aerosol particles $\left(C_{\text {gen }}^{\mathrm{N}}(\right.$ tot $\left.)\right)$ and number concentrations of particle of various sizes $\left(C_{\mathrm{gen}}^{\mathrm{N}}(d)\right)$ at the lowest point in the Postojna Cave in winter 2010

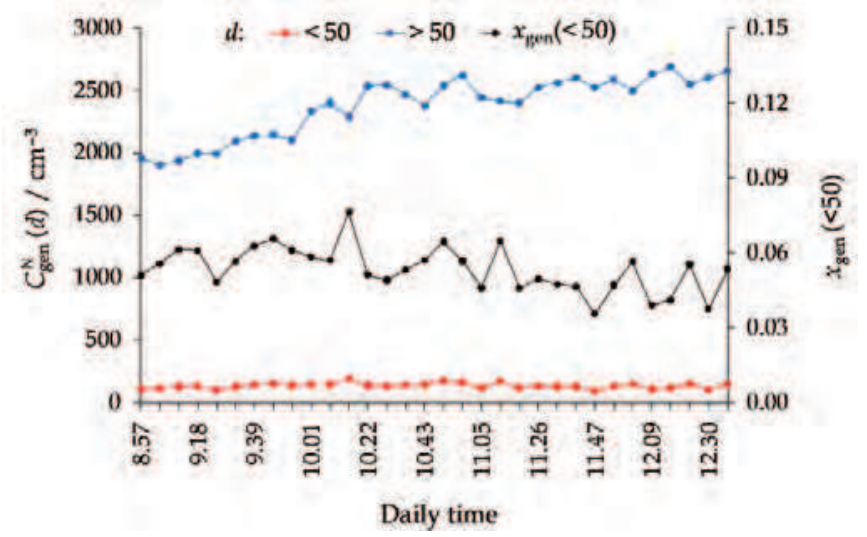

Fig. 9. Time run of number concentrations of general aerosol particles smaller than $50 \mathrm{~nm}$ $\left(C_{\text {gen }}^{\mathrm{N}}(\langle 50))\right.$ and larger than that $\left.\left(C_{\text {gen }}^{\mathrm{N}}(\rangle 50\right)\right)$, and the fraction of the smaller ones $\left(x_{\text {gen }}(\langle 50))\right.$ at the lowest point in the Postojna Cave in winter 2010

Figure 10a shows $C_{\mathrm{Rn}}^{\mathrm{A}}$ and $F$, and Fig. 10b, $C_{\mathrm{RnDP}}^{\mathrm{A}}$ and fun. As expected from previous measurements in winter (Vaupotič, 2008b), $C_{R n}^{A}$ and fun are lower and $F$ is higher than in summer. The cave air is less stagnant in winter than in summer, because of the inflow of fresh air, and therefore lower $F$ values would be expected than in summer. The opposite is true due to the higher concentration of general aerosols in winter than in summer and consequently higher availability for RnDP to be present in air. During the period when general aerosols were also monitored, fun values were around 0.05 (Fig. 10b), resulting in a $D_{\text {CFD value of } 13.5}$ mSv WLM-1 according to Eq. 6 (as compared with $43.6 \mathrm{mSv}^{-1} \mathrm{WLM}^{-1}$ in summer) or $11.4 \mathrm{mSv}$ $\mathrm{WLM}^{-1}$ according to Eq. 7 (as compared with $77.4 \mathrm{mSv}^{\mathrm{WLM}}{ }^{-1}$ in summer, and compared with $D_{\mathrm{CFE}}=5 \mathrm{mSv} \mathrm{WLM}^{-1}$ for workplaces). Fig. 11a shows for this period the individual number concentrations of the unattached RnDP and Fig. 11b, of the attached RnDP atoms. The ratios of 
the numbers of unattached and attached ${ }^{218} \mathrm{Po},{ }^{214} \mathrm{~Pb}$ and ${ }^{214} \mathrm{Bi}$ atoms are $0.22,0.04$ and 0.018 , respectively, in the beginning, and $0.27,0.04$ and 0.021 at the end of measurement, being practically constant during measurement, in contrast to the summer situation, when the value for ${ }^{218}$ Po decreased markedly. This ratio is also by far the highest for ${ }^{218}$ Po in winter.

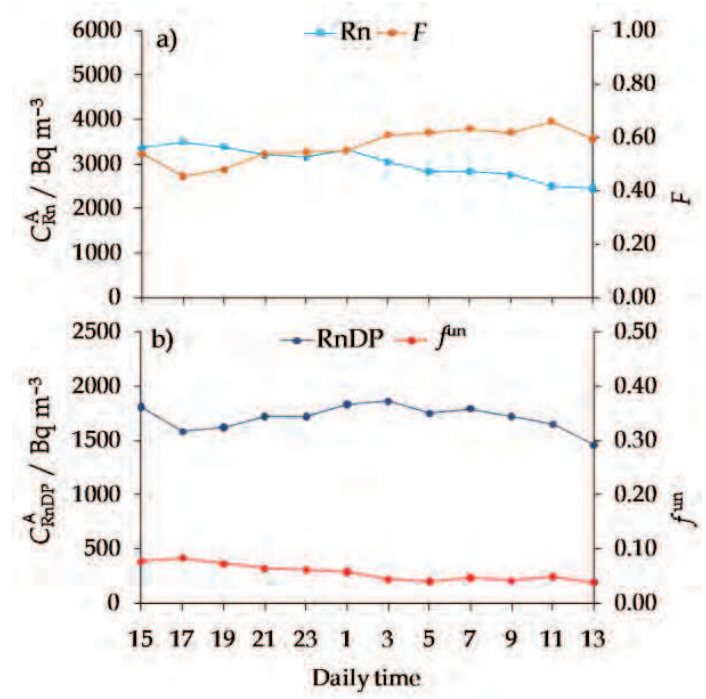

Fig. 10. Results of a continuous radon measurement at the lowest point in the Postojna Cave in winter 2010: a) radon activity concentration $\left(C_{R n}^{A}\right)$ and equilibrium factor between radon and its decay products $(F)$, and $b$ ) equivalent equilibrium activity concentration of radon decay products $\left(C_{\mathrm{RnDP}}^{\mathrm{A}}\right)$ and fraction of unattached decay products (fun)

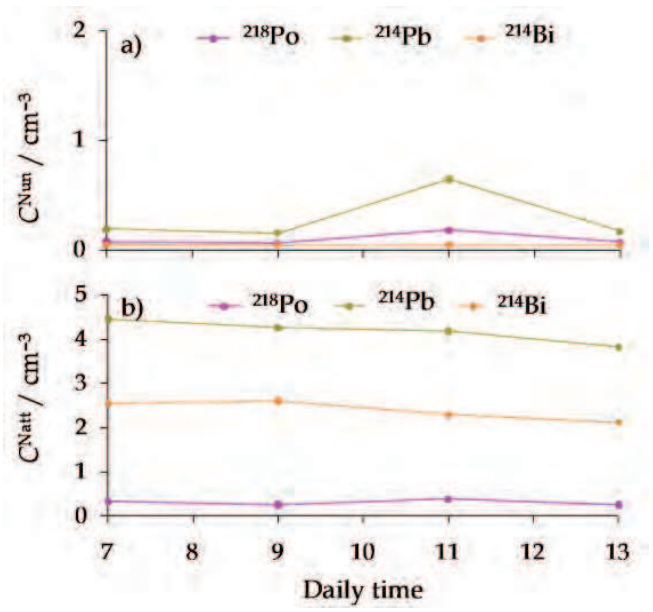

Fig. 11. Number concentrations of ${ }^{218} \mathrm{Po},{ }^{214} \mathrm{~Pb}$ and ${ }^{214} \mathrm{Bi}$ atoms for the period in Fig. 10 when general aerosols were also monitored: $\mathrm{a})$ in the unattached form $\left(C_{214 \mathrm{Po}}^{\mathrm{Nun}}, C_{214 \mathrm{~Pb}}^{\mathrm{Nun}}\right.$ and $\left.C_{214 \mathrm{Bi}}^{\mathrm{Nun}}\right)$, and b) attached form $\left(C_{214 \mathrm{Po}}^{\mathrm{Natt}}, C_{214 \mathrm{~Pb}}^{\mathrm{Natt}}\right.$ and $\left.C_{214 \mathrm{Bi}}^{\mathrm{Natt}}\right)$ 
Under winter conditions (Fig. 12), the number concentration of the $<50 \mathrm{~nm}$ particles is about twenty times lower than that of larger ones, and their total surface area is about four hundred times smaller than that of larger ones. The probability for RnDP atoms to be associated with smaller particles is thus substantially reduced as compared with the summer conditions, and consequently, the majority of RnDP atoms appear in the attached form.

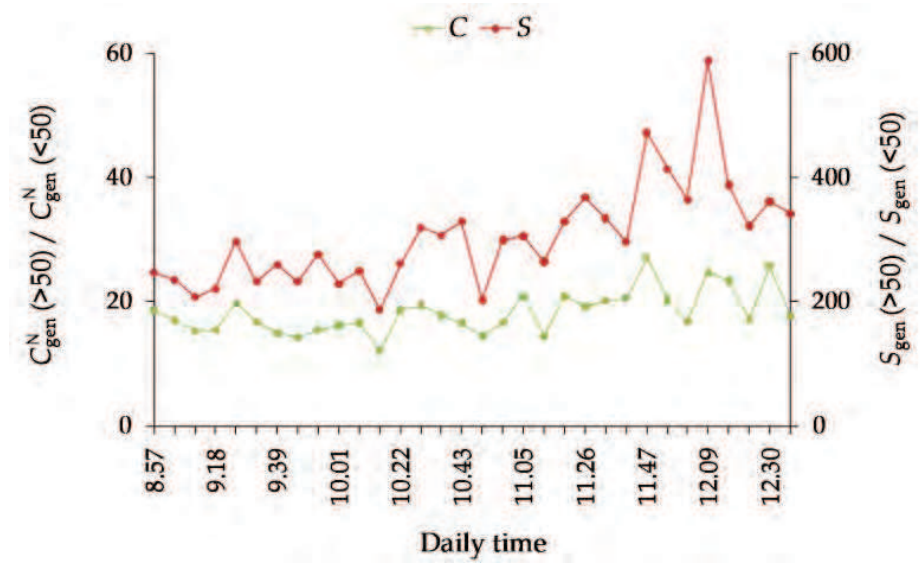

Fig. 12. Ratio of the number concentration of general aerosol particles larger than $50 \mathrm{~nm}$ $\left.\left(C_{\text {gen }}^{\mathrm{N}}(\rangle 50\right)\right)$ to that of smaller ones $\left(C_{\text {gen }}^{\mathrm{N}}(\langle 50))\right.$, and ratio of the total surface area of all particles larger than $\left.50 \mathrm{~nm}\left(S_{\text {gen }}(\rangle 50\right)\right)$ to that of all particles smaller than $50 \mathrm{~nm}\left(S_{\text {gen }}(\langle 50))\right.$ in a volume unit for the measurement in winter 2010

These results show why fun values are higher in summer than in winter. The reason also originates from the size distribution of general aerosols in the cave, and not merely from their total number concentration. In summer, the contribution of particles smaller than 50 $\mathrm{nm}$, to which the unattached RnDP are associated, is predominant, while in winter it is minor in the total aerosol concentration. When applying the dosimetric approach, the calculated dose conversion factor, and hence the dose a tourist guide or visitor receives during a visit (without mentioning that $C_{R n D P}^{A}$ is higher in summer than in winter) is more than three times greater in summer than in winter.

\subsection{Dwelling}

Only results for selected period are presented here. Fig. 13a shows the total number concentration (2-h average values) of general aerosols $\left(C_{\text {gen }}^{\mathrm{N}}(\right.$ tot $\left.)\right)$ and geometric means of particle diameter $\left(\mathrm{GM}_{\mathrm{pd}}\right)$, and Fig. $13 \mathrm{~b}$, the fractions of the $<10 \mathrm{~nm}$ particles $\left(x_{\text {gen }}(\langle 10))\right.$ and $<20 \mathrm{~nm}$ particles $\left(x_{\text {gen }}(\langle 20))\right.$ during the period indicated, in outdoor air in the courtyard in front of the kitchen. For the entire period of measurement the following arithmetic means of the measured parameters were obtained: $C_{\text {gen }}^{\mathrm{N}}($ tot $)=6900 \pm 3200 \mathrm{~cm}^{-3}, \mathrm{GM}_{\mathrm{pd}}=63 \pm 19 \mathrm{~nm}$, $x_{\text {gen }}\left(\langle 10)=0.03 \pm 0.04, x_{\text {gen }}\left(\langle 20)=0.12 \pm 0.09, C_{\mathrm{RnDP}}^{\mathrm{A}}=10 \pm 9 \mathrm{~Bq} \mathrm{~m}^{-3}\right.\right.$ and fun $=0.11 \pm 0.08 . C_{\text {gen }}^{\mathrm{N}}$ (tot) varies from about 2000 to 20,000 $\mathrm{cm}^{-3}$ (Fig. 13a). In both urban (Noble et al., 2003; Young \& Keeler, 2007; Y. Wang et al., 2010) and semi-rural (F. Wang et al., 2010) areas, two daily 
peaks were found, one in the morning and the other in late afternoon, coinciding with the traffic rush hours. In our case diurnal variation shows two maxima, one at around midnight and the other between $8 \mathrm{~h}$ and $16 \mathrm{~h}$. The morning growth of $C_{\text {gen }}^{\mathrm{N}}($ tot), with a concomitant decrease in $\mathrm{GM}_{\mathrm{pd}}$, is caused by activities at the farm, e. g., running cars, tractors and other farming equipment, these being lowest at noon. The afternoon simultaneous increase of both $C_{\text {gen }}^{\mathrm{N}}$ (tot) and $\mathrm{GM}_{\mathrm{pd}}$ is presumably related to nucleation caused by solar radiation (Noble et al., 2003; Minoura \& Takekawa, 2005; Smerajec et al., 2010) and particle growth by coagulation (Kulmala et al., 2004; Kumar et al., 2010b). Decrease in $C_{\text {gen }}^{\mathrm{N}}$ (tot) after its midnight maximum as ascribed to the deposition of smaller particles, resulting in increasing $\mathrm{GM}_{\mathrm{pd}}$. Fig. 14 shows the particle size distribution at the $\mathrm{GM}_{\mathrm{pd}}$ maximum and minimum on October 9 (at points 1 and 2 in Fig. 13) and October 10 (at points 3 and 4 in Fig. 13).

For the above period, Fig. 15 shows diurnal variation in $C_{\mathrm{RnDP}}^{\mathrm{A}}$, with maxima overnight and minima at noon. An expected (Butterweck et al., 1992; Cheng et al., 1997; Meisenberg \& Tschiersch, 2009), though only approximate, coincidence of fun minima and $C_{\text {gen }}^{\mathrm{N}}$ (tot) maxima (Fig. 13a) is seen.

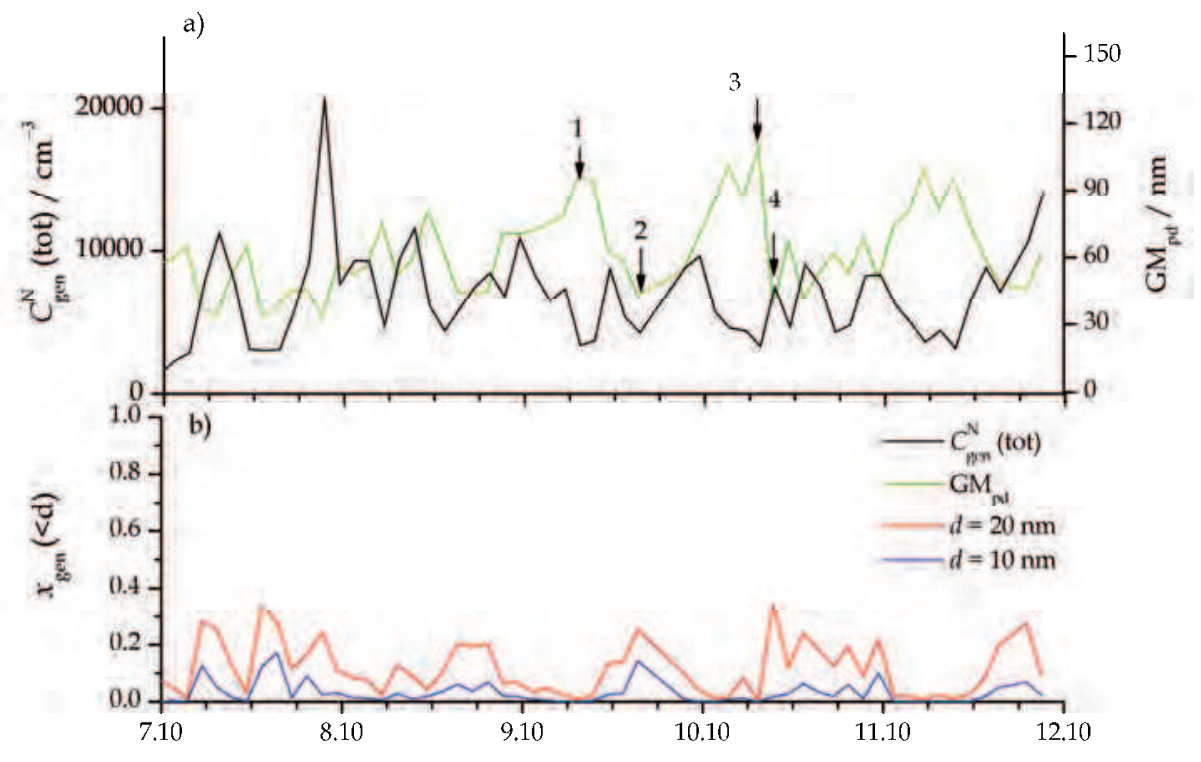

Date in 2010

Fig. 13. Time run of: a) the total number concentration of general aerosol particles $\left(C_{\text {gen }}^{\mathrm{N}}(\right.$ tot $\left.)\right)$ and geometric mean values of their diameters $\left.\left(\mathrm{GM}_{\mathrm{pd}}\right), \mathrm{b}\right)$ number fraction of particles smaller than $10 \mathrm{~nm}\left(x_{\text {gen }}(\langle 10))\right.$ and smaller than $20 \mathrm{~nm}\left(x_{\text {gen }}(\langle 20))\right.$, in outdoor air in front of the dwelling in the period October 7-10 

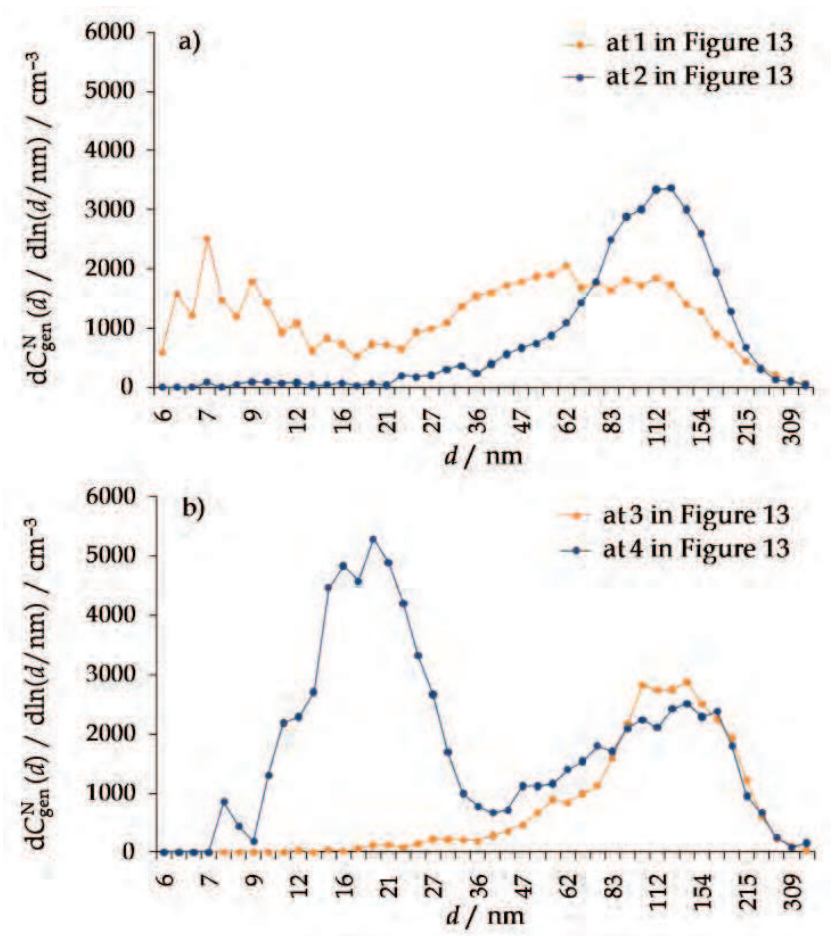

Fig. 14. Number size distributions $\left(\mathrm{d} C_{\text {gen }}^{\mathrm{N}}(d) / \mathrm{d} \ln (d / \mathrm{nm})\right)$ of general aerosol particles in outdoor air in front of the dwelling at the maximum and minimum $\mathrm{GM}_{\mathrm{pd}}$ values in the time run of $C_{\text {gen }}^{\mathrm{N}}$ (tot) in Fig. 13 a) on October 9 (marked by arrows 1 and 2) and b) on October 10 (marked by arrows 3 and 4 )

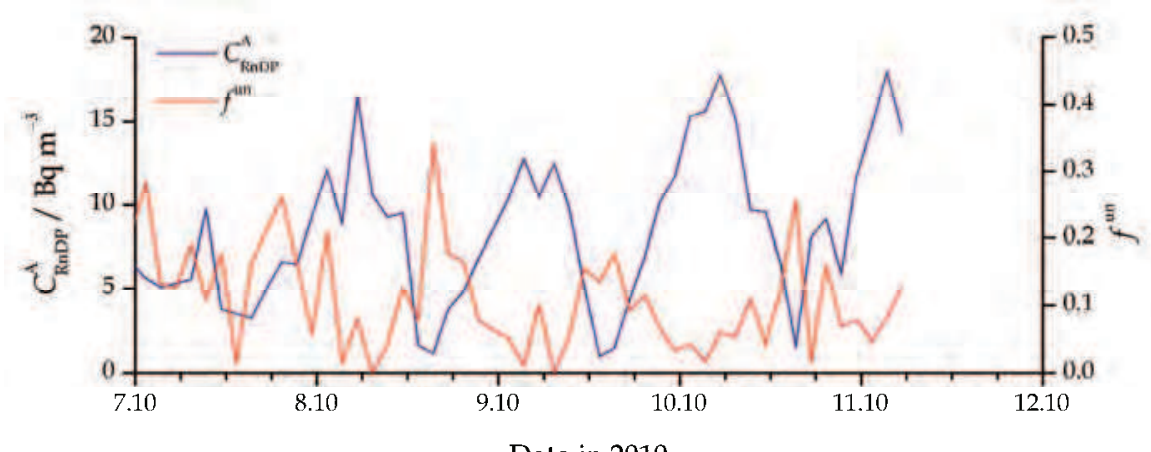

Date in 2010

Fig. 15. Diurnal variations of the equivalent equilibrium activity concentration of radon decay products $\left(C_{\mathrm{RnDP}}^{\mathrm{A}}\right)$ and fraction of the unattached decay products (fun), in outdoor air in front of the dwelling in the period October 7-10 
Figure 16 shows the time series of a) $C_{\text {gen }}^{\mathrm{N}}($ tot $)$ and $\mathrm{GM}_{\mathrm{pd}}$ and $\left.\mathrm{b}\right), x_{\text {gen }}\left(\langle 10)\right.$ and $x_{\text {gen }}(\langle 20)$, and Fig. 17, of a) $C_{\mathrm{Rn}}^{\mathrm{A}}$ and $F$, and b), $C_{\mathrm{RnDP}}^{\mathrm{A}}$ and fun, in indoor air of the basement kitchen for the period indicated. During this period, the window was open from 16.50 on October 28 to 23.30 on October and was kept closed otherwise. On October 29 at 20.05 and 20.45 a toaster was used for $10 \mathrm{~min}$ each time. The following arithmetic means of the measured parameters were obtained for a) the period of closed window, excluding the period of using the toaster: $C_{\text {gen }}^{\mathrm{N}}($ tot $)=5100 \pm 1700 \mathrm{~cm}^{-3}, \mathrm{GM}_{\mathrm{pd}}=60 \pm 12 \mathrm{~nm}, x_{\text {gen }}\left(\langle 10)=0.02 \pm 0.04, x_{\text {gen }}(\langle 20)=0.10 \pm 0.09\right.$, $C_{\mathrm{RnDP}}^{\mathrm{A}}=116 \pm 35 \mathrm{~Bq} \mathrm{~m}^{-3}$ and fun $\left.=0.18 \pm 0.06, \mathrm{~b}\right)$ the period with the window open: $C_{\text {gen }}^{\mathrm{N}}($ tot $)=$ $11,500 \pm 6600 \mathrm{~cm}^{-3}, \mathrm{GM}_{\mathrm{pd}}=52 \pm 11 \mathrm{~nm}, x_{\text {gen }}\left(\langle 10)=0.03 \pm 0.02, x_{\text {gen }}\left(\langle 20)=0.14 \pm 0.08, C_{\mathrm{RnDP}}^{\mathrm{A}}=22 \pm 5\right.\right.$ $\mathrm{Bq} \mathrm{m}^{-3}$ and $f \mathrm{un}=0.22 \pm 0.06$, and $\left.\mathrm{c}\right)$ the period while using the toaster: $C_{\text {gen }}^{\mathrm{N}}($ tot $)=$ $207,000 \pm 51,000 \mathrm{~cm}^{-3}, \mathrm{GM}_{\mathrm{pd}}=61 \pm 6 \mathrm{~nm}, x_{\text {gen }}\left(\langle 10)=0.01 \pm 0.001, x_{\text {gen }}\left(\langle 20)=0.03 \pm 0.01, C_{\mathrm{RnDP}}^{\mathrm{A}}=\right.\right.$ $89 \pm 22 \mathrm{~Bq} \mathrm{~m}^{-3}$ and fun $=0.09 \pm 0.02$.

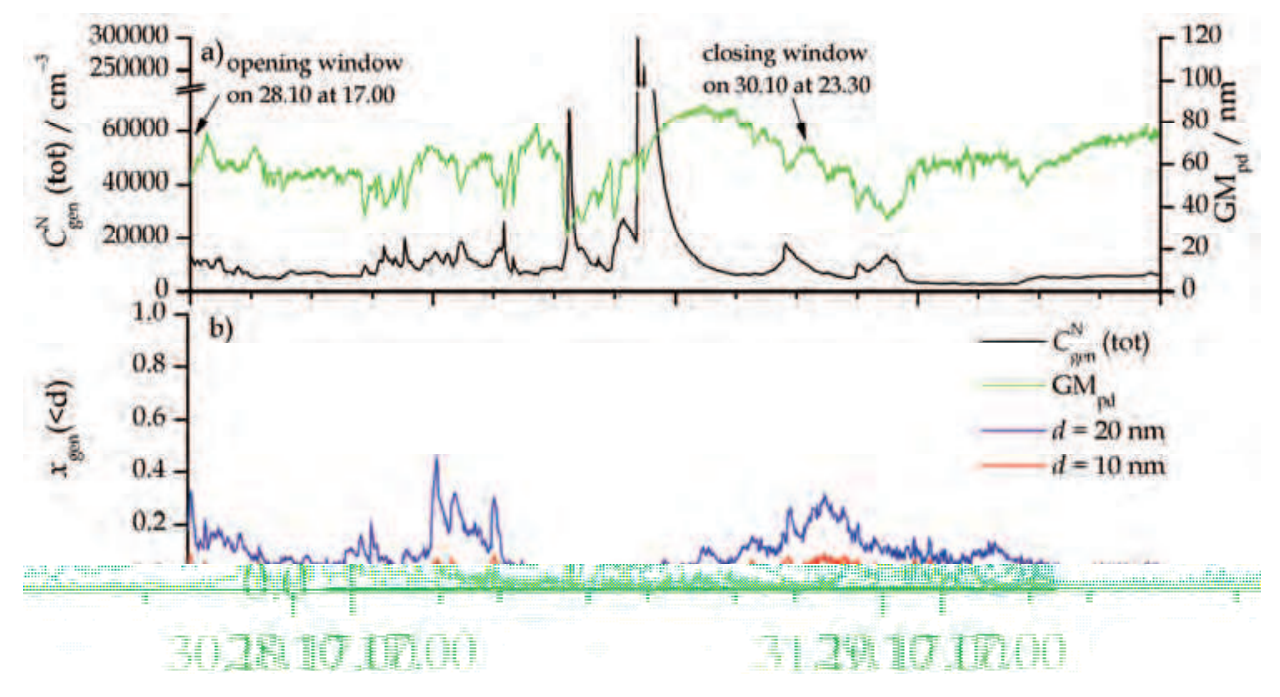

Fig. 16. Time run of: a) total number concentration of general aerosol particles $\left(C_{\text {gen }}^{\mathrm{N}}(\right.$ tot $\left.)\right)$ and geometric mean values of their diameters $\left.\left(\mathrm{GM}_{\mathrm{pd}}\right), \mathrm{b}\right)$ number fraction of particles smaller than $10 \mathrm{~nm}\left(x_{\text {gen }}(\langle 10))\right.$ and smaller than $20 \mathrm{~nm}\left(x_{\text {gen }}(\langle 20))\right.$, in indoor air in the kitchen in the period October 28-31 


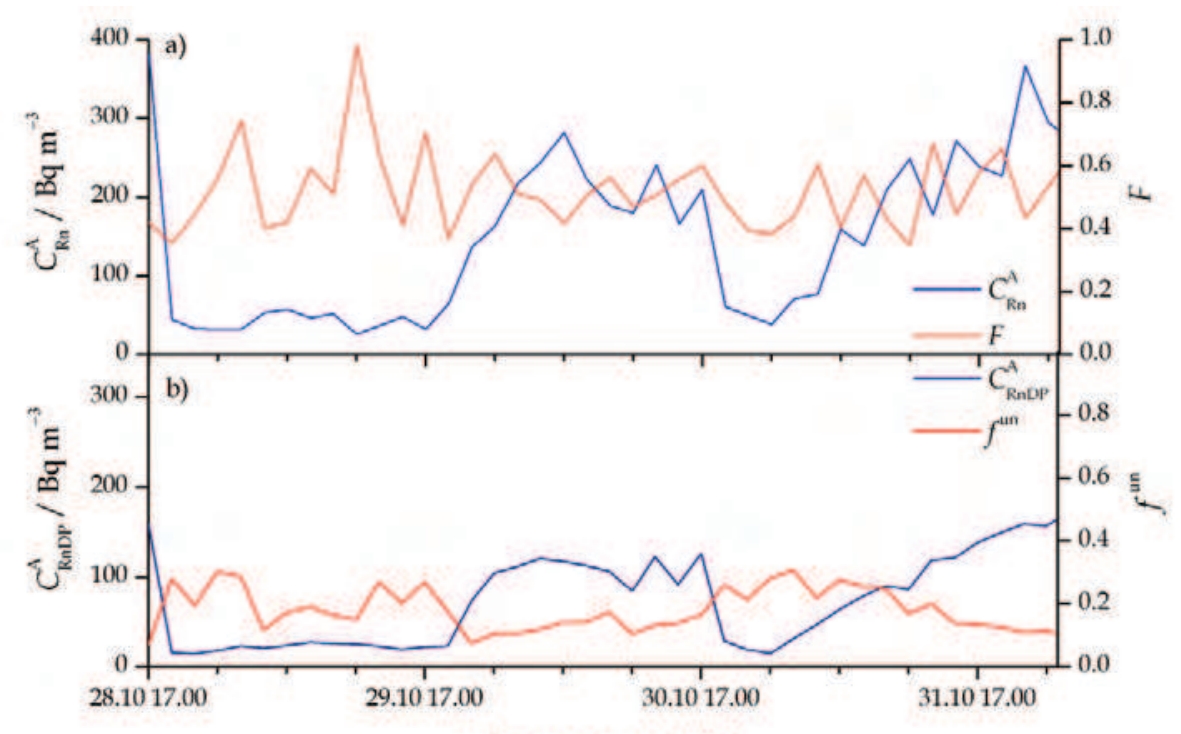

Date and time in 2010

Fig. 17. Diurnal variations of: a) radon activity concentration $\left(C_{R n}^{A}\right)$ and equilibrium factor between radon and its decay products $(F)$, and $b$ ) equivalent equilibrium activity concentration of radon decay products $\left(C_{\mathrm{RnDP}}^{\mathrm{A}}\right)$ and fraction of unattached decay products (fun), in indoor air in the kitchen in the period October 28-31

As expected, opening the window, both $C_{\mathrm{Rn}}^{\mathrm{A}}$ and $C_{\mathrm{RnDP}}^{\mathrm{A}}$ suddenly dropped and remained low until the window was closed at 18.50 on October 29 , when they started to increase (Fig. 17). The effect of closing window is presented in Fig. 18. Because $\mathrm{GM}_{\mathrm{pd}}$ in outdoor air is low at 16.50 (Fig. 13a), the inflow of outdoor air shifted the size distribution towards lower values (Fig. 19), thus reducing $\mathrm{GM}_{\mathrm{pd}}$ and increasing $x_{\text {gen }}(\langle 20)$ indoors (Fig. 18b). The decrease in number concentrations of all three RnDP in the attached form is a consequence of the decrease in $C_{\mathrm{RnDP}}^{\mathrm{A}}$ (Fig. 18d). The frequency of EQF measurement is too low to follow such abrupt changes and therefore the fun response (Fig. 18c) is not necessarily correct. A general trend of $\mathrm{GM}_{\mathrm{pd}}$ increase is seen. Neither $C_{\mathrm{gen}}^{\mathrm{N}}$ (tot) nor $\mathrm{GM}_{\mathrm{pd}}$ reflect the diurnal variations observed outdoors (Fig. 13a), thus proving good air tightness of the door and window.

On closing the window, only a slight increase in $\mathrm{GM}_{\text {pd }}$ was observed (Fig. 20a), as shown also in Fig. 21. GM $\mathrm{Gd}_{\mathrm{pd}}$ steadily increases and thus $x_{\text {gen }}(\langle 20)$ decreases (Fig. 20b). As expected, decreasing $C_{\text {gen }}^{\mathrm{N}}$ (tot) (Fig. 20a) is accompanied by increasing fun (Fig. 20c), and increasing $C_{\mathrm{RnDP}}^{\mathrm{A}}$ (Fig. 17), by increasing number concentrations of RnDP (Figs. 20d, e). 


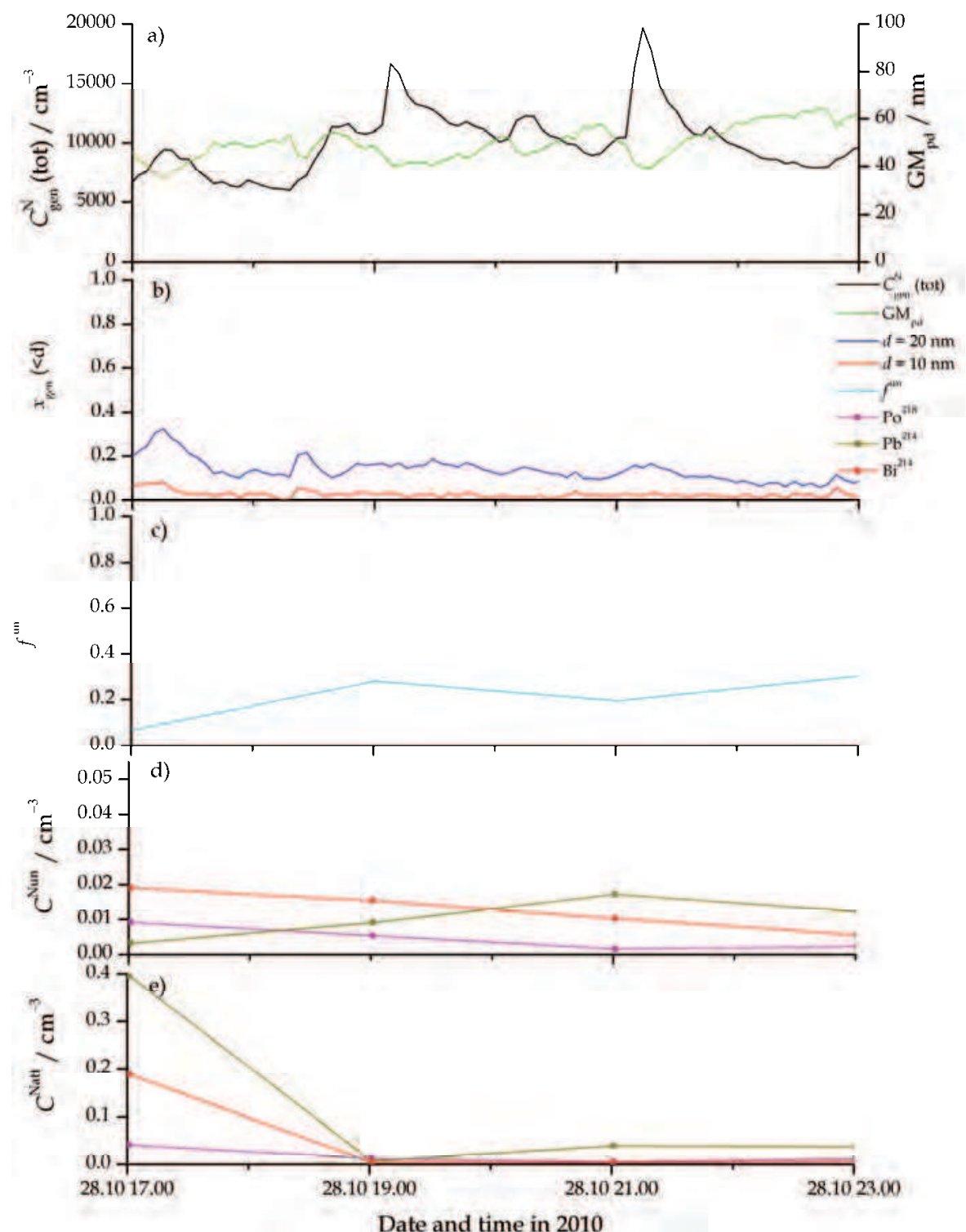

Fig. 18. Time run of: a) total number concentration of general aerosol particles $\left(C_{\text {gen }}^{\mathrm{N}}(\right.$ tot $\left.)\right)$ and geometric mean values of their diameters $\left.\left(\mathrm{GM}_{\mathrm{pd}}\right), \mathrm{b}\right)$ number fraction of particles smaller than $10 \mathrm{~nm}\left(x_{\text {gen }}(\langle 10))\right.$ and smaller than $20 \mathrm{~nm}\left(x_{\text {gen }}(\langle 20)), \mathrm{c}\right)$ the unattached fraction of $\operatorname{RnDP}(f \mathrm{un}), \mathrm{d})$ number concentrations of the unattached RnDP atoms $\left(C_{218 \mathrm{Po}}^{\mathrm{Nun}}, C_{214 \mathrm{~Pb}}^{\mathrm{Nun}}\right.$ and $\left.C_{214 \mathrm{Bi}}^{\mathrm{Nun}}\right)$, and e) number concentrations of the attached RnDP atoms $\left(C_{218 P_{0}}^{\text {Natt }}, C_{214 \mathrm{~Pb}}^{\text {Natt }}\right.$ and $\left.C_{214 \mathrm{Bi}}^{\text {Natt }}\right)$, in indoor air in the kitchen in the period October 28-29 (period of opening the window in the kitchen at 16.50 on October 28) 


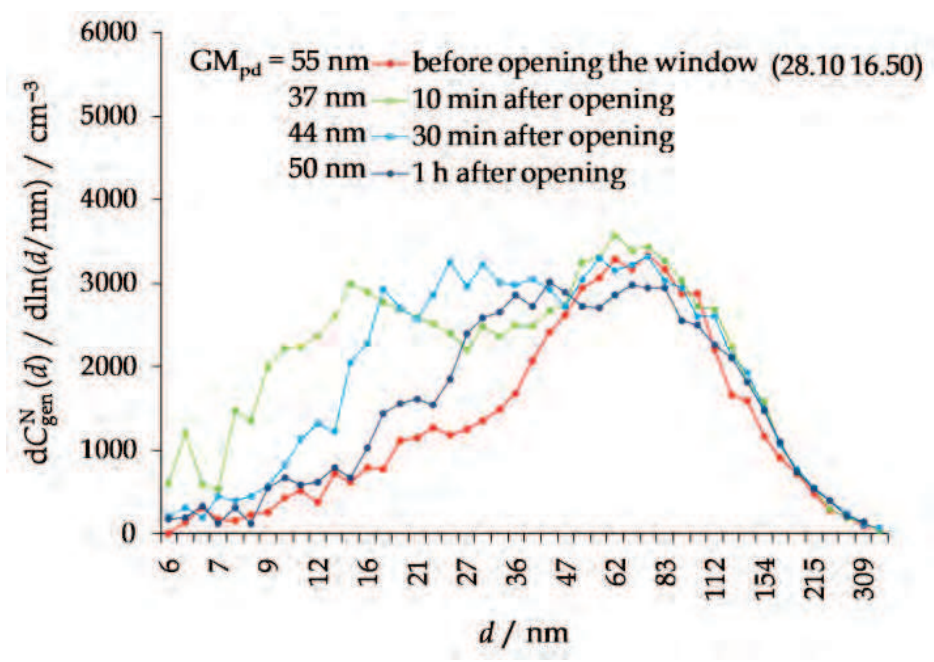

Fig. 19. Number size distributions $\left(\mathrm{d} C_{\text {gen }}^{\mathrm{N}}(d) / \mathrm{d} \ln (d / \mathrm{nm})\right)$ of general aerosol particles in indoor air before and during opening the window in the kitchen 


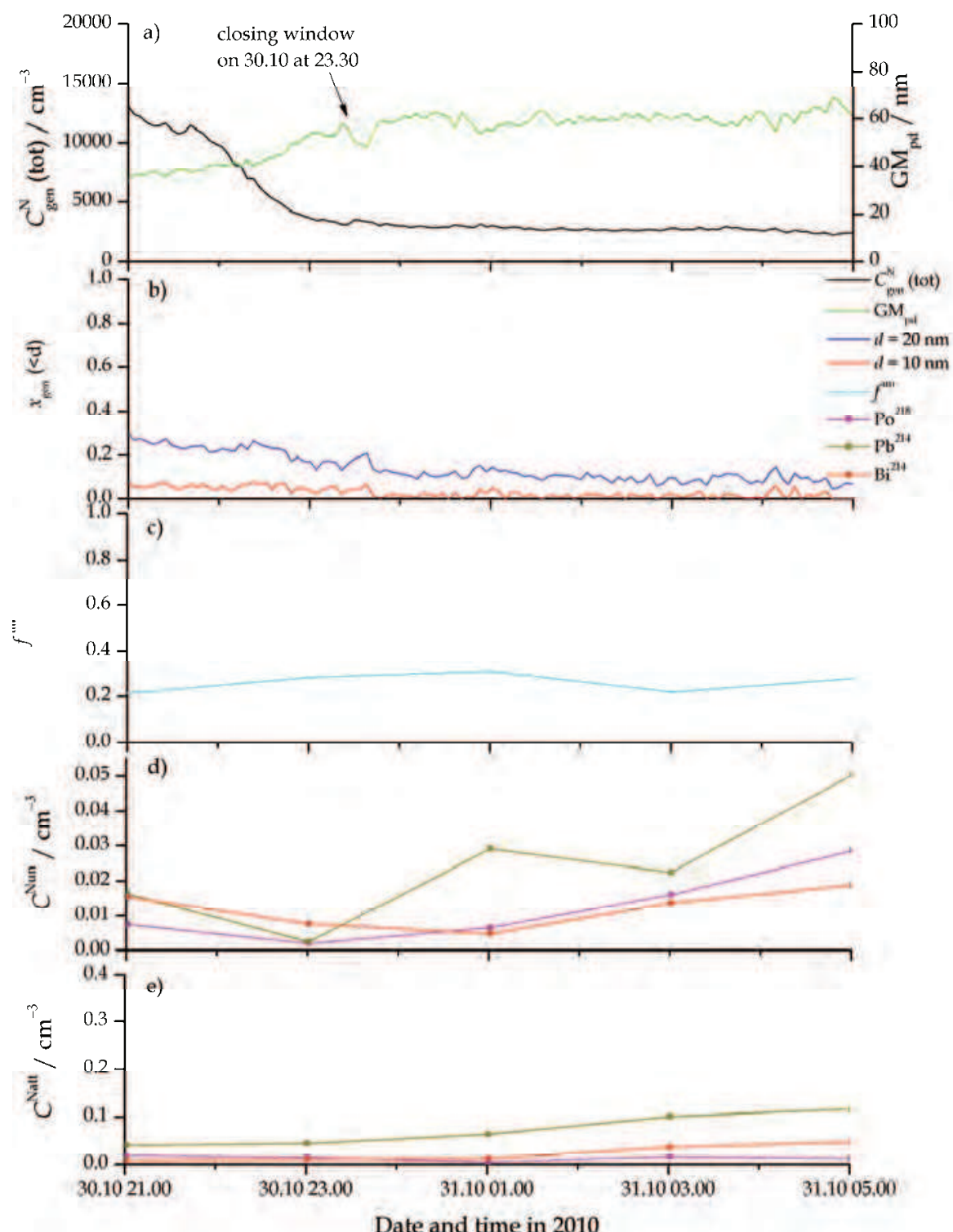

Fig. 20. Time run of: a) total number concentration of general aerosol particles $\left(C_{\text {gen }}^{\mathrm{N}}(\right.$ tot $\left.)\right)$ and geometric mean values of their diameters $\left.\left(\mathrm{GM}_{\mathrm{pd}}\right), \mathrm{b}\right)$ number fraction of particles smaller than $10 \mathrm{~nm}\left(x_{\text {gen }}(\langle 10))\right.$ and smaller than $20 \mathrm{~nm}\left(x_{\text {gen }}(\langle 20)), \mathrm{c}\right)$ the fraction of the unattached RnDP (fun), d) number concentrations of the unattached RnDP atoms $\left(C_{218 \mathrm{Po} o}^{\mathrm{Nun}}, C_{214 \mathrm{~Pb}}^{\mathrm{Nu}}\right.$ and $\left.C_{214 \mathrm{Bi}}^{\mathrm{Nu}}\right)$, and e) number concentrations of attached RnDP atoms $\left(C_{218 \mathrm{PO}}^{\text {Natt }}, C_{214 \mathrm{~Pb}}^{\text {Natt }}\right.$ and $\left.C_{214 \mathrm{Bi}}^{\text {Natt }}\right)$, in indoor air in the kitchen in the period October 30-31 (period of closing the window in the kitchen at 23.30 on October 30 ) 


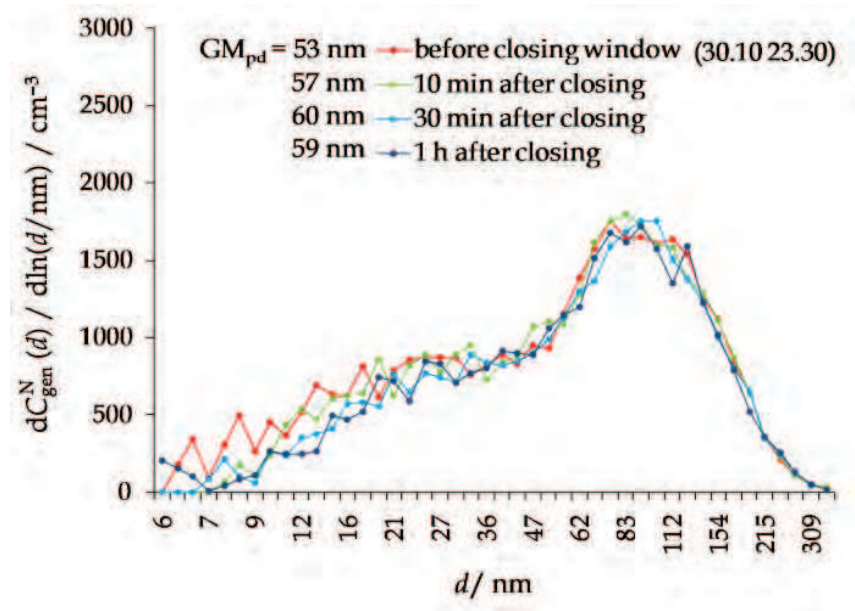

Fig. 21. Number size distributions $\left(\mathrm{d} C_{\text {gen }}^{\mathrm{N}}(d) / \mathrm{d} \ln (d / \mathrm{nm})\right)$ of general aerosol particles in indoor air before and after closing the window in the kitchen

An abrupt and very large increase in $C_{\text {gen }}^{\mathrm{N}}$ (tot) (reaching 300,000 $\mathrm{cm}^{-3}$ ) on October 29 (Fig. 16a) was caused by using the toaster at 20.05. A closer look at the situation is presented in Fig. 22 in which the $C_{\text {gen }}^{\mathrm{N}}$ (tot) peak is split into two because of two consecutive toasting of 10 min reveals that the size distribution of particles was not significantly changed during toasting, but was only slightly shifted towards higher sizes afterwards (Fig. 23). After toasting was finished, $\mathrm{GM}_{\mathrm{pd}}$ started to increase steadily, presumably because of the particle growth, estimated to be $2-3 \mathrm{~nm} \mathrm{~h}^{-1}$ for urban area in October (Birmili et al., 2003; Kulmala et al., 2004). 


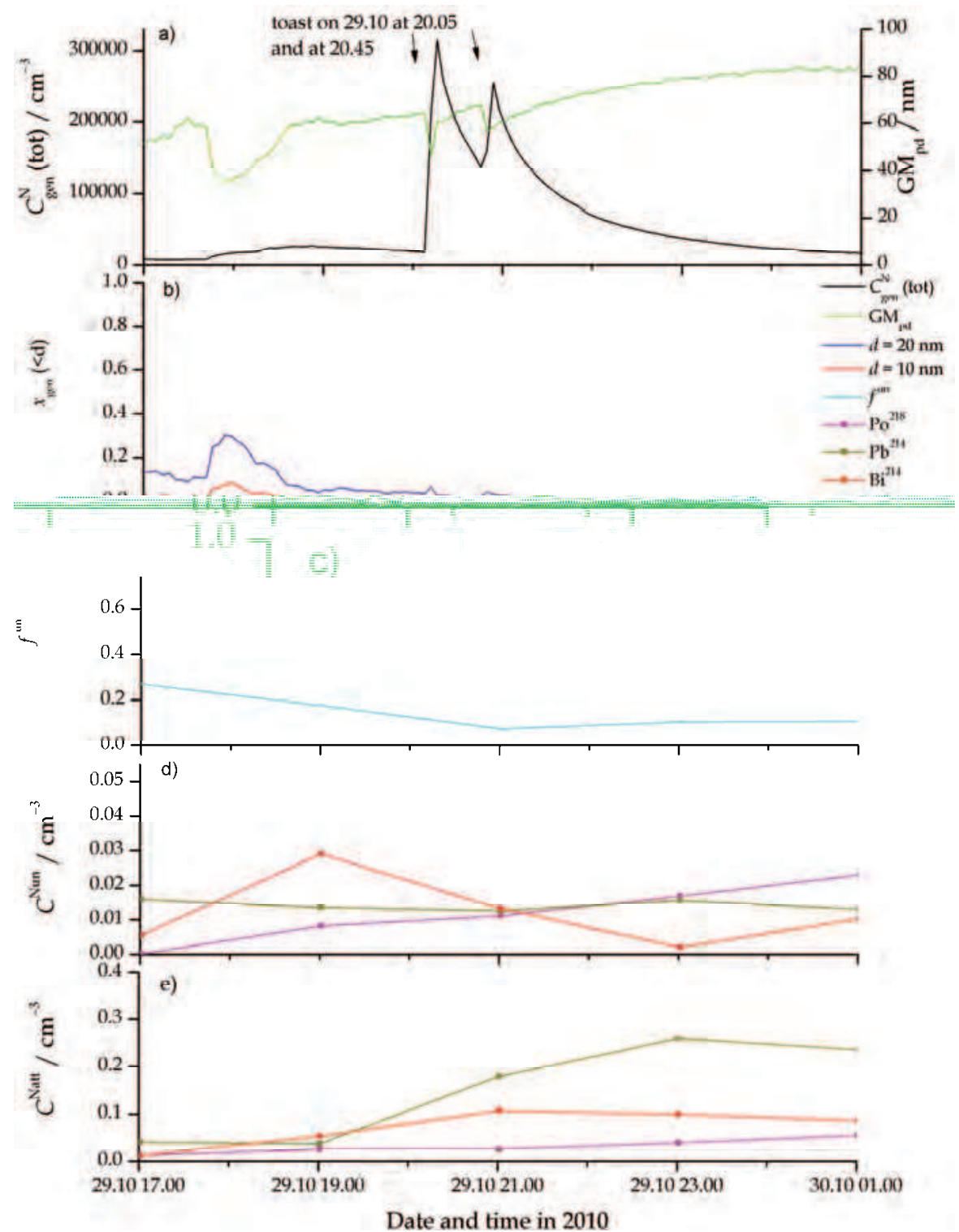

Fig. 22. Time run of: a) total number concentration of general aerosol particles $\left(C_{\text {gen }}^{\mathrm{N}}(\right.$ tot $\left.)\right)$ and geometric mean values of their diameters $\left.\left(\mathrm{GM}_{\mathrm{pd}}\right), \mathrm{b}\right)$ number fraction of particles smaller than $10 \mathrm{~nm}\left(x_{\text {gen }}(\langle 10))\right.$ and smaller than $20 \mathrm{~nm}\left(x_{\text {gen }}(\langle 20)), \mathrm{c}\right)$ the fraction of the unattached RnDP (fun), d) number concentrations of the unattached RnDP atoms $\left(C_{218 \mathrm{Po}}^{\mathrm{Nun}}, C_{214 \mathrm{~Pb}}^{\mathrm{Nun}}\right.$ and $\left.C_{214 \mathrm{Bi}}^{\mathrm{Nun}}\right)$, and e) number concentrations of attached RnDP atoms $\left(C_{218 \mathrm{Po}}^{\mathrm{Natt}}, C_{214 \mathrm{~Pb}}^{\mathrm{Natt}}\right.$ and $\left.C_{214 \mathrm{Bi}}^{\mathrm{Natt}}\right)$, in indoor air in the kitchen in the period October 30-31 (periods of using a toaster in the kitchen from 20.05 to 20.15 and from 20.45 to 20.55 on October 29) 


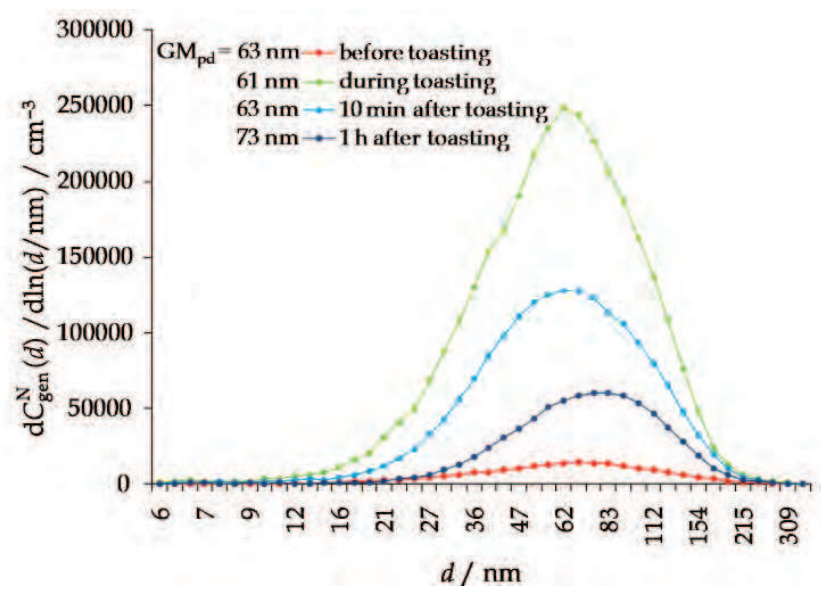

Fig. 23. Number size distributions $\left(\mathrm{d} C_{\text {gen }}^{\mathrm{N}}(d) / \mathrm{d} \ln (d / \mathrm{nm})\right)$ of general aerosol particles in indoor air in the kitchen during using a toaster

Figure 24a shows diurnal variations of $C_{\text {gen }}^{\mathrm{N}}$ (tot) and $\mathrm{GM}_{\mathrm{pd}}$, and Fig. $24 \mathrm{~b}, x_{\text {gen }}(\langle 10)$ and $x_{\text {gen }}\left(\langle 20)\right.$, and Fig. 25a, $C_{\mathrm{Rn}}^{\mathrm{A}}$ and F, and Fig. 25b, $C_{\mathrm{RnDP}}^{\mathrm{A}}$ and fun, in indoor air of the basement kitchen for the period indicated. During this period, the window was kept closed and a candle was burning from 22.20 on January 5 to 1.50 on January 6 . Except for the period of burning the candle, the following arithmetic means of the measured parameters were obtained: $C_{\text {gen }}^{\mathrm{N}}($ tot $)=6900 \pm 4000 \mathrm{~cm}^{-3}, \mathrm{GM}_{\mathrm{pd}}=55 \pm 10 \mathrm{~nm}, x_{\text {gen }}\left(\langle 10)=0.02 \pm 0.03, x_{\text {gen }}(\langle 20)=\right.$ $0.11 \pm 0.08, C_{\mathrm{RnDP}}^{\mathrm{A}}=78 \pm 18 \mathrm{~Bq} \mathrm{~m}^{-3}$ and fun $=0.16 \pm 0.04$, and during the candle period: $C_{\mathrm{gen}}^{\mathrm{N}}($ tot $)=$ $897,000 \pm 186,000 \mathrm{~cm}^{-3}, \mathrm{GM}_{\mathrm{pd}}=10 \pm 1 \mathrm{~nm}, x_{\text {gen }}\left(\langle 10)=0.64 \pm 0.08, x_{\text {gen }}\left(\langle 20)=0.91 \pm 0.03, C_{\mathrm{RnDP}}^{\mathrm{A}}=\right.\right.$ $127 \pm 27 \mathrm{~Bq} \mathrm{~m}{ }^{-3}$ and $f u n=0.10 \pm 0.01$. An enormous $C_{\text {gen }}^{\mathrm{N}}$ (tot) peak (reaching $1,200,000 \mathrm{~cm}^{-3}$ ), accompanied by a sudden decrease in $\mathrm{GM}_{\mathrm{pd}}$, appeared during burning the candle (Fig. 24a). A closer look is presented in Fig. 26. The abrupt decrease in $\mathrm{GM}_{\mathrm{pd}}$ (Fig. 26a), shown also in Fig 27, is concomitant with a substantial increase in both $x_{\text {gen }}\left(\langle 10)\right.$ and $x_{\text {gen }}(\langle 20)$, even exceeding 0.60 and 0.90 , respectively. This high fraction of small particles to which the unattached $\mathrm{RnDP}$ are related should result in high fun values, based on our experience gained in the Postojna Cave. In contrast, fun was even slightly lowered, as predicted by the inverse fun $-C_{\text {gen }}^{\mathrm{N}}$ (tot) relationship, although not as pronounced as expected (Porstendörfer, 1996; Cheng et al., 1997). Although in the period without toasting an inverse fun $-C_{\text {gen }}^{\mathrm{N}}$ (tot) correlation is observed (Fig. 28b), this is not true for the entire period shown in Fig. 28a where similar fun values are seen at both low and very high $C_{\text {gen }}^{\mathrm{N}}($ tot $)$ values. Neither fun $x_{\text {gen }}\left(\langle 10)\right.$ nor fun $-x_{\text {gen }}(\langle 20)$ correlations can be confirmed (Fig. 29). Generally, higher fun values are associated with higher values of $\mathrm{GM}_{\mathrm{pd}}$ as expected, but several low fun values are found also in the high $\mathrm{GM}_{\mathrm{pd}}$ region, similar to those during the candle burning with $\mathrm{GM}_{\mathrm{pd}}$ of about $10 \mathrm{~nm}$ (Fig. 30). The explanation may be based on the plots in Fig. 31. During the candle burning $C_{\text {gen }}^{\mathrm{N}}\left(\langle 10)\right.$ is about 2 fold higher than $\left.C_{\text {gen }}^{\mathrm{N}}(\rangle 10\right)$ and, on the other hand, the total surface area of smaller particles in a volume unit $\left(S_{\text {gen }}^{\mathrm{N}}(\langle 10))\right.$ is about 5 fold lower than that of the larger ones $\left.\left(S_{\text {gen }}^{\mathrm{N}}(\rangle 10\right)\right)$ (Fig. 31a). In the case of $<20 \mathrm{~nm}$ particles, the following situation is evident (Fig. 31b): $C_{\text {gen }}^{\mathrm{N}}\left(\langle 20)\right.$ is about 10 fold higher than $\left.C_{\text {gen }}^{\mathrm{N}}(\rangle 20\right)$, but on the other hand the total surface area of smaller particles in a volume unit $\left(S_{\text {gen }}^{N}(\langle 20))\right.$ is about 2 


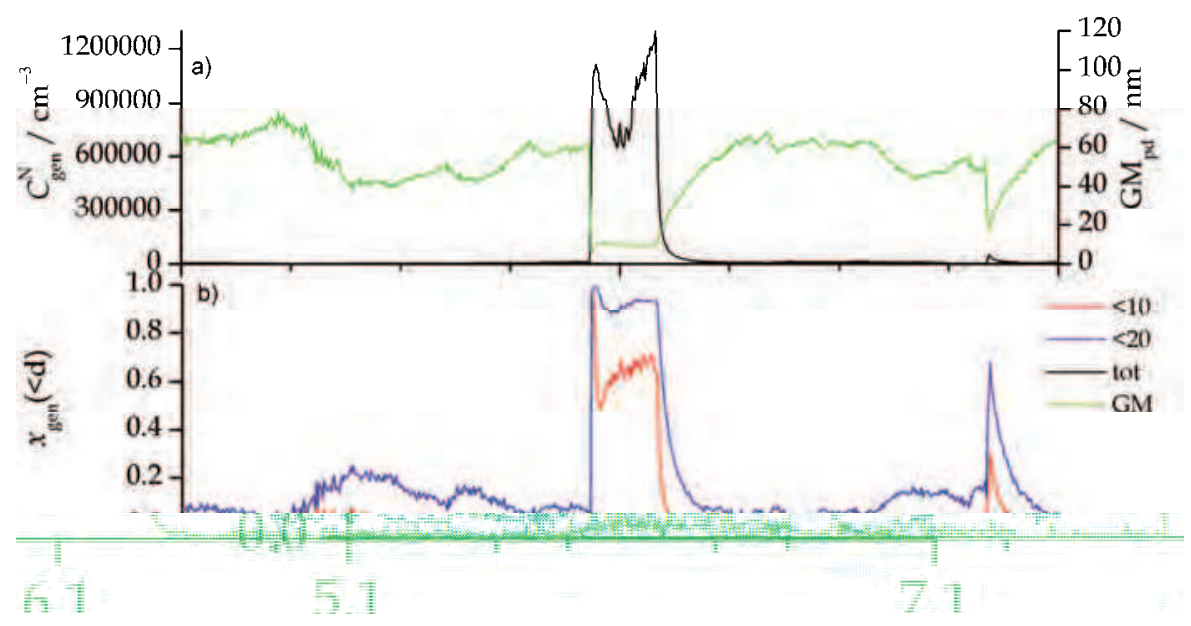

Fig. 24. Time run of: a) total number concentration of general aerosol particles $\left(C_{\text {gen }}^{\mathrm{N}}(\right.$ tot $\left.)\right)$ and geometric mean values of their diameters $\left.\left(\mathrm{GM}_{\mathrm{pd}}\right), \mathrm{b}\right)$ number fraction of particles smaller than $10 \mathrm{~nm}\left(x_{\text {gen }}(\langle 10))\right.$ and smaller than $20 \mathrm{~nm}\left(x_{\text {gen }}(\langle 20))\right.$, in indoor air in the kitchen in the period January 5-7

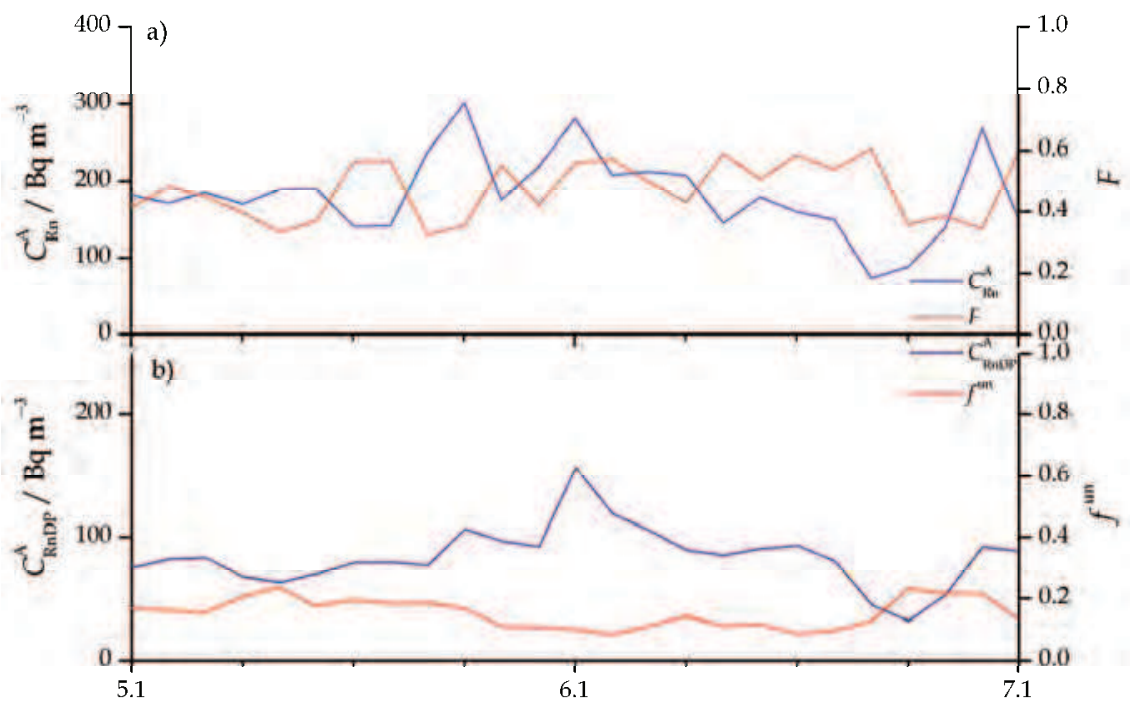

Date in 2011

Fig. 25. Diurnal variations of: a) radon activity concentration $\left(C_{R n}^{A}\right)$ and equilibrium factor between radon and its decay products $(F)$, and $b$ ) equivalent equilibrium activity concentration of radon decay products $\left(C_{\mathrm{RnDP}}^{\mathrm{A}}\right)$ and fraction of unattached decay products (fun), in indoor air in the kitchen in the period January 5-7 


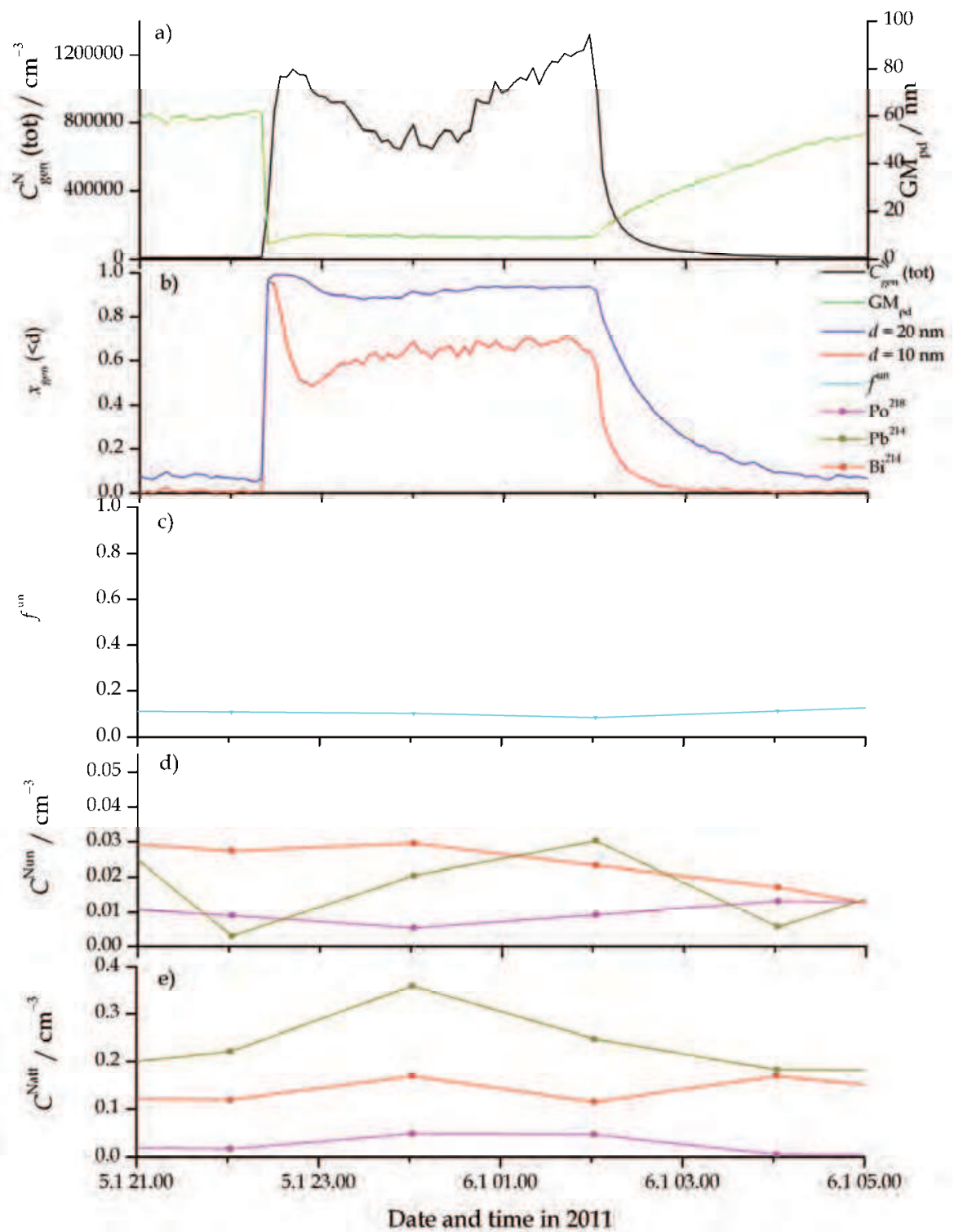

Fig. 26. Time run of: a) total number concentration of general aerosol particles $\left(C_{\text {gen }}^{\mathrm{N}}(\right.$ tot $\left.)\right)$ and geometric mean values of their diameters $\left.\left(\mathrm{GM}_{\mathrm{pd}}\right), \mathrm{b}\right)$ number fraction of particles smaller than $10 \mathrm{~nm}\left(x_{\text {gen }}(\langle 10))\right.$ and smaller than $20 \mathrm{~nm}\left(x_{\text {gen }}(\langle 20)), \mathrm{c}\right)$ the unattached decay products (fun), d) number concentrations of the unattached RnDP atoms $\left(C_{218 \mathrm{Po}}^{\mathrm{Nun}}, C_{214 \mathrm{~Pb}}^{\mathrm{Nun}}\right.$ and $\left.C_{214 \mathrm{Bi}}^{\mathrm{Nun}}\right)$, and e) number concentrations of attached RnDP atoms $\left(C_{218 \mathrm{Po}}^{\mathrm{Nat}}, C_{214 \mathrm{~Pb}}^{\mathrm{Natt}}\right.$ and $\left.C_{214 \mathrm{Bi}}^{\mathrm{Natt}}\right)$, in indoor air in the kitchen in the period January 5-6 (period of burning a candle in the kitchen from 22.20 on January 5 to 1.50 on January 6 ) 
fold lower than that of the larger ones $\left.\left(S_{\text {gen }}^{\mathrm{N}}(\rangle 20\right)\right)$. Therefore, a preference of RnDP atoms to be associated with particles smaller than $20 \mathrm{~nm}$ and smaller than $10 \mathrm{~nm}$, with resulting lower fun values, cannot be expected. Another reason for this may also be a very small number concentration of the particles of about $1 \mathrm{~nm}$ size to which most unattached RnDP are related, but whose concentration can be only guessed from Fig. 27a, but not measured with our device. In addition, process of the RnDP formation takes time and therefore fun cannot follow fast changes in aerosol composition adequately.

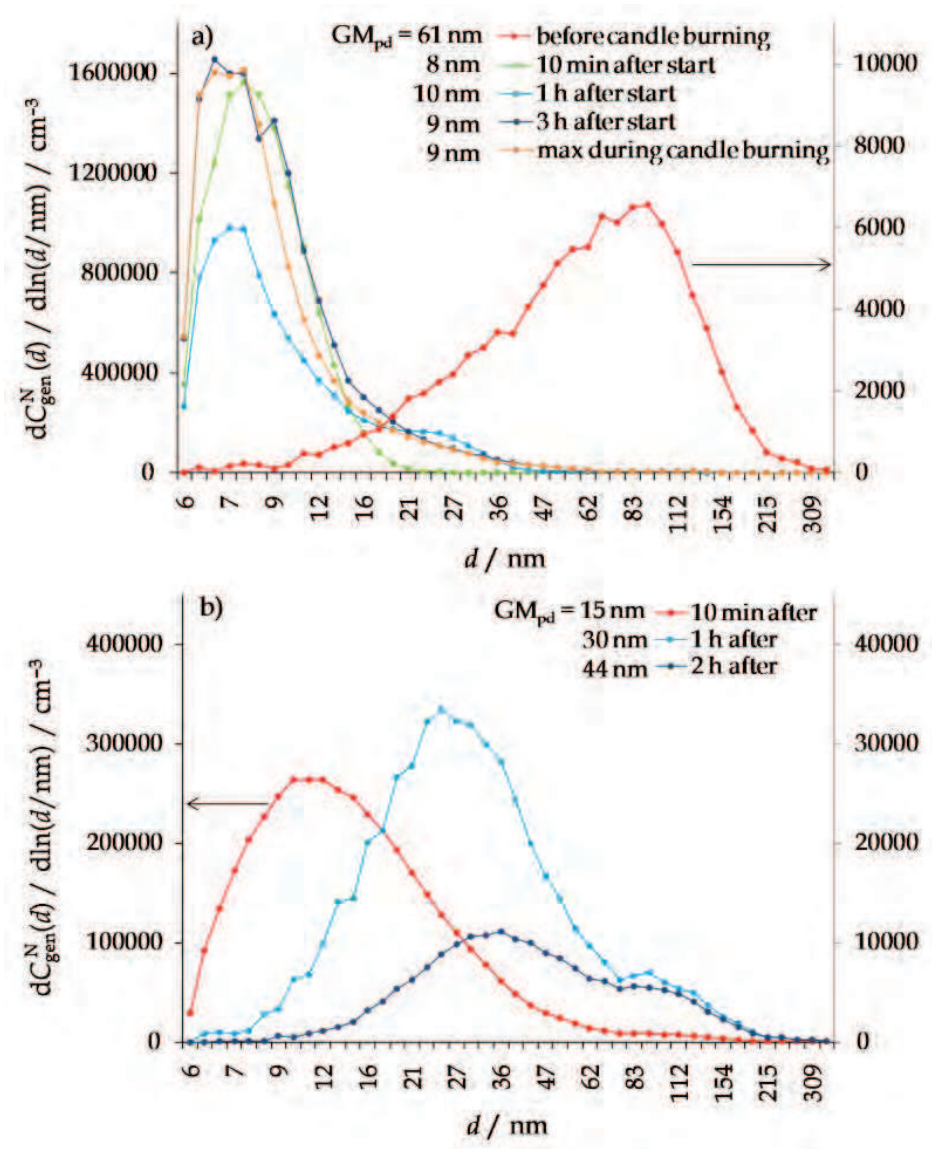

Fig. 27. Number size distributions $\left(\mathrm{d} C_{\text {gen }}^{\mathrm{N}}(d) / \mathrm{d} \ln (d / \mathrm{nm})\right)$ of general aerosol particles in indoor air a) before and during burning a candle and $b$ ) after burning a candle 


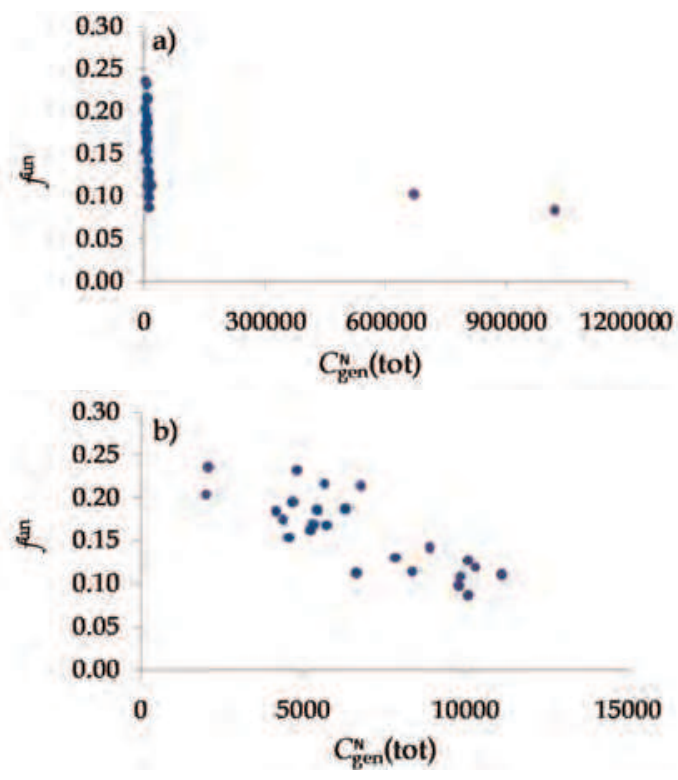

Fig. 28. Relationship between the fraction (fun) of the unattached RnDP and total number concentration of general aerosols $\left(C_{\text {gen }}^{\mathrm{N}}(\right.$ tot $\left.)\right)$ in indoor air in the kitchen: a) for the entire period January 5-7 and b) for the period January 5-7, except during the candle burning
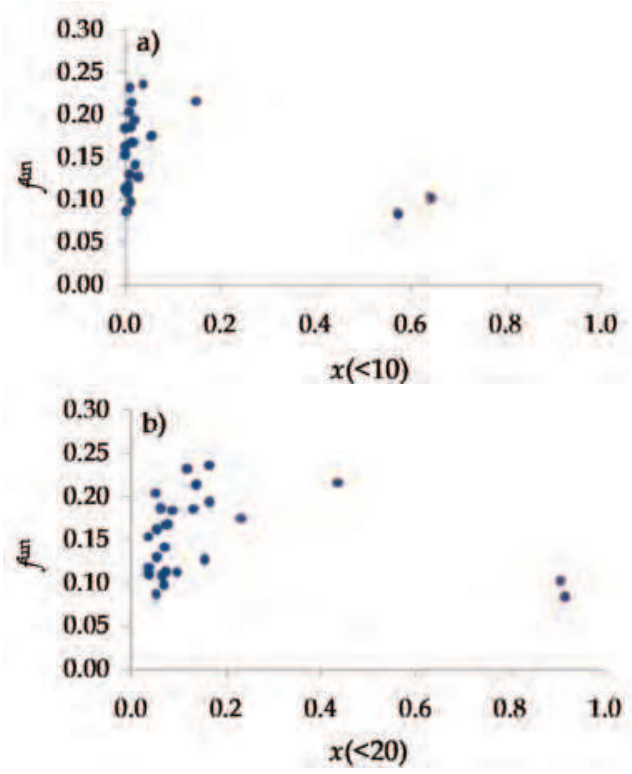

Fig. 29. Relationship between the fraction (fun) of the unattached RnDP, in indoor air in the kitchen for the entire period January $5-7$, and number fraction of general aerosol particles: a) smaller than $10 \mathrm{~nm}(x(<10))$ and b) smaller than $20 \mathrm{~nm}(x(<20))$ 


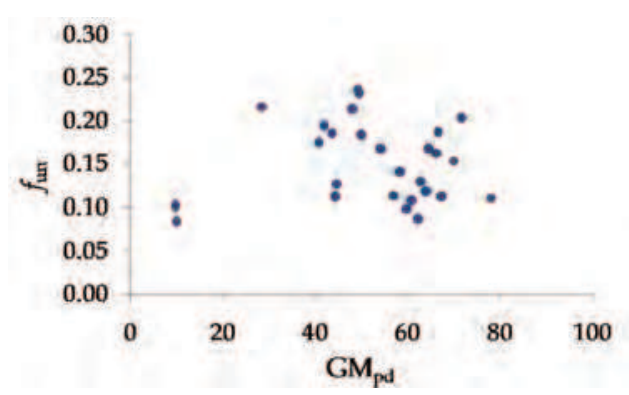

Fig. 30. Relationship between the fraction (fun) of the unattached RnDP and the geometric mean of general aerosol particles $\left(\mathrm{GM}_{\mathrm{pd}}\right)$, in indoor air in the kitchen for the entire period January 5-7

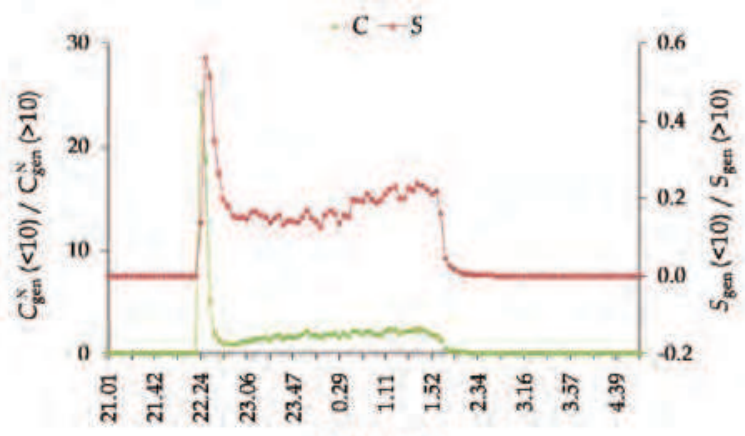

Daily time

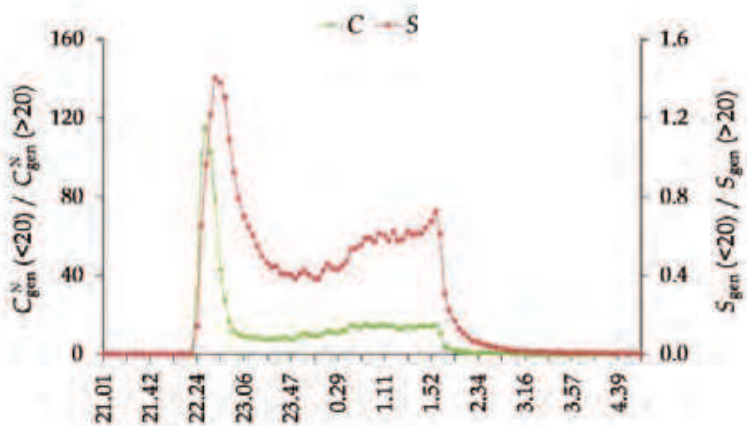

Daily time

Fig. 31. Indoor air in the kitchen, entire period January 5-7: a) ratio of the number concentration of aerosol particles smaller than $10 \mathrm{~nm}\left(C_{\text {gen }}^{\mathrm{N}}(\langle 10))\right.$ to that of larger ones $\left.\left(C_{\text {gen }}^{\mathrm{N}}(\rangle 10\right)\right)$, and ratio of the total surface area of all particles smaller than $10 \mathrm{~nm}\left(S_{\text {gen }}(\langle 10))\right.$ to the total surface area of all particles larger than $\left.10 \mathrm{~nm}\left(S_{\text {gen }}(\rangle 10\right)\right)$ in a volume unit, and b) ratio of the number concentration of aerosol particles smaller than $20 \mathrm{~nm}\left(C_{\text {gen }}^{\mathrm{N}}(\langle 20))\right.$ to that of larger ones $\left.\left(C_{\text {gen }}^{\mathrm{N}}(\rangle 20\right)\right)$, and ratio of the total surface area of all particles smaller than 20 $\mathrm{nm}\left(S_{\text {gen }}(\langle 20))\right.$ to the total surface area of all particles larger than $\left.20 \mathrm{~nm}\left(S_{\text {gen }}(\rangle 20\right)\right)$ in a volume unit 


\section{Conclusion}

Radon decay products (RnDP) and general aerosols were monitored in parallel in the air of the Postojna Cave (size range 10-1100 $\mathrm{nm}$ ) in summer and in winter and in a dwelling (size range 5-350 nm) in a suburban area in an autumn - winter period, focused on the unattached fraction of RnDP (fun), the key parameter in radon dosimetry. In the cave, the total number concentration of the aerosol particles $\left(C_{\text {gen }}^{\mathrm{N}}(\right.$ tot $\left.)\right)$ during visits in summer was lower $\left(700 \mathrm{~cm}^{-3}\right)$ than in winter $\left(2800 \mathrm{~cm}^{-3}\right)$, and was dominated by the $<50 \mathrm{~nm}$ particles (related to the unattached RnDP) in summer and by the $>50 \mathrm{~nm}$ particles (related to the attached RnDP) in winter. This explains why fun values (and thus the calculated dose conversion factors) are several times higher in summer than in winter. The difference is caused by an enhanced inflow of fresh air, driven in winter by higher air temperature in the cave than outdoors, introducing outdoor larger aerosols particles into the cave.

In the outdoor air at the dwelling, $C_{\text {gen }}^{\mathrm{N}}$ (tot) varies in the range from $2000 \mathrm{~cm}^{-3}$ to $20,000 \mathrm{~cm}^{-3}$, with two daily maxima, one at around midnight and the other between $8 \mathrm{~h}$ and $16 \mathrm{~h}$. The geometric mean of particle diameter is highest, at $100-120 \mathrm{~nm}$, at the $C_{\text {gen }}^{\mathrm{N}}$ (tot) minimum in early morning, while it is lowest at the $C_{\text {gen }}^{\mathrm{N}}($ tot) minima, $30-40 \mathrm{~nm}$.

In the dwelling, $C_{\text {gen }}^{\mathrm{N}}($ tot) during periods without any human activity was on average 4000 $7000 \mathrm{~cm}^{-3}$ and increased markedly while toasting bread and burning a candle, reaching $300,000 \mathrm{~cm}^{-3}$ and 1,200,000 $\mathrm{cm}^{-3}$, respectively. Even at these high $C_{\text {gen }}^{\mathrm{N}}$ (tot) values, fun did not fall below its value at $C_{\text {gen }}^{\mathrm{N}}$ (tot) of about $10,000 \mathrm{~cm}^{-3}$. Although during the candle burning more than $60 \%$ of particles were smaller than $10 \mathrm{~nm}$ and more than $90 \%$, smaller than 20 $\mathrm{nm}$, their total surface areas were three to two times, respectively, lower than those of the larger ones. Therefore, a significant enhancement of preferential association of RnDP atoms to smaller particles, and thus decreasing fun, can hardly be expected.

\section{Acknowledgement}

The study was financed by the Slovenian Research Agency within the project contract no. J10745. The author thanks Ms. Mateja Smerajec for her help in operating the Grimm instrument and for data evaluations.

\section{References}

Agus, E. L., Young D. T., Lingard, J. J. N., Smalley, R. J., Tate, J. E., Goodman, P. S. \& Tomlin, A. S. (2007). Factors influencing particle number concentrations, size distributions and modal parameters at a roof-level and roadside site in Leicester, UK. Science of the Total Environment, 386, pp. 65-82.

Alföldy, B., Giechaskiel, B., Hofmann, W. \& Drossinos, Y. (2009). Size-distribution dependent lung deposition of diesel exhaust particles. Journal of Aerosol Science, 40, pp. 652-663.

Amman, M. \& Butscher, H. (1990). Characterization of ultrafine aerosol particles in Mt. Etna emissions. Bulletin of Volcanology, 52, pp. 577-583.

Anastasio, M. \& Martin, C. T. (2001). Atmospheric nanoparticles, In: Nanoparticles and the Environment, J. F. Bafield \& A. Navrotsky, (Eds.), pp. 293-349, Mineralogical Society of America, vol. 44. 
Balcázar, M., Chávez, A., Piña-Villalpando, G., Alfaro, M. \& Mendoza, D. (1999). Radon decay products attached to clothes in a nuclear laboratory. Radiation Measurements, 31, pp. 337-324.

Baltensperger, U. \& Nyeki, S. (1998). Atmospheric aerosols, In: Physical and Chemical Properties of Aerosols, I. Colbeck, (Ed.), pp. 280-330, Blackie Academic \& Professional, an imprint of Thomas Science, ISBN 075140402 0, Bury St Edmunds, Great Britain.

Birchall, A. \& James, A. C. (1994). Uncertainty analysis of the effective dose per unit exposure from radon progeny and implications for ICRP risk-weighting factors. Radiation Protection Dosimetry, 53, pp. 133-140.

Birmili, W., Berrensheim, H., Plass-Dülmer, C., Eslte, T., Gilge, S., Wiedensohlner, A. \& Uhrner, U. (2003). The Hohenpeissenberg aerosol formation experiment (HAFEX): A long-term study including size-resolved aerosol, $\mathrm{H}_{2} \mathrm{SO}_{4}, \mathrm{OH}$, and monoterpens measurements. Atmospheric Chemistry and Physics, 3, pp. 361-376.

Busek, P. R. \& Adachi, K. (2008). Nanoparticles in the atmosphere. Elements, 4, pp. 398-394.

Butterweck, G., Porstendörfer, J., Reineking, A. \& Kesten, J. (1992). Unattached fraction and the aerosol size distribution of the radon progeny in a natural cave and mine atmosphere. Radiation Protection Dosimetry, 45, pp. 167-170.

Cheng, Y. S., Chen, T. R., Wasiolek, P. T. \& Van Engen, A. (1997). Radon and radon progeny in the Carlsbad Caverns. Aerosol Science and Technology, 26, pp. 74-92.

Cheng, Y. S., Chen, T. R., Yeh, H. C., Bigu, J., Holub, R., Tu, K., Knutson, E. O. \& Falk, R. (2000). Intercomparison of activity size distribution of thoron progeny and a mixture of radon and thoron progeny. Journal of Environmental Radioactivity, 51, pp. 59-78.

Chu, K.-D. \& Hopke, P. K. (1988). Neutralization kinetics for polonium-218. Environmental Science and Technology, 22, pp. 711-717.

Cigna, A. A. (2005). Radon in caves. International Journal of Speleology, 34, pp. 1-8.

Colbeck, I. (1998). Introduction to aerosol science, In: Physical and Chemical Properties of Aerosols, I. Colbeck, (Ed.), pp. 1-30, Blackie Academic \& Professional, an imprint of Thomas Science, ISBN 075140402 0, Bury St Edmunds, Great Britain.

Dankelmann, V., Reineking, A. \& Porstendörfer, J. (2001). Determination of neutralization rate of 218Po ions in air. Radiation Protection Dosimetry, 94, pp. 353-357.

Darby, S., Hill, D., Auvinen, A., Barros-Dios, J. M., Baysson, H., Bochicchio, F., Deo, H., Falk, R., Forastiere, F., Hakama, M., Heid, I., Kreienbrock, R., Kreuzer, M., Lagarde, F., Mäkeläinen, I., Muirhead, C., Oberaigner, W. Pershagen, G., Ruano-Ravina, A., Ruosteenoja, E., Schaffrath Rosario, A., Tirmarche, M., Tomášek, A., Whitley, E., Wichmann, H.-E. \& Doll, R. (2005). Radon in homes and risk of lung cancer: collaborative analysis of individual data for 13 European case-control studies. British Medical Journal, 330, pp. 223-227.

Dobos, E., Borbérly-Kiss, I., Kertész, Zs., Szabó, Gy. \& Koltay, E. (2009). Debrecen, Hungary on the fine-fraction aerosol map of Europe. Journal of Radioanalytical and Nuclear Chemistry, 279, pp. 143-157.

Etiope, G. \& Martinelli, G. (2002). Migration of carrier and trace gases in the geosphere: an overview. Physics of the Earth and Planetary Interiors, 129, pp. 185-204. 
Field, S. M. (2007). Risks to cavers and cave workers from exposure to low-level ionizing a radiation from ${ }^{222 R n}$ decay in caves. Journal of Cave and Karst Studies, 69, pp. 207228.

Fukutsu, K., Yamada, Y. \& Tokonami, S. (2004). Newly designed graded screen array for particle size measurements of unattached radon progeny products. Review of Scientific Instruments, 75, pp. 783-787.

Goldstein, S. D. \& Hopke, P. K. (1985). Environmental neutralization of polonium-218. Environmental Science and Technology, 19, pp. 146-150.

Gregorič, A., Zidanšek, A. \& Vaupotič, J. (2011). Dependence of radon levels in the Postojna Cave on outdoor air temperature. Natural Hazards and Earth System Sciences (in press).

Hakl, J., Hunyadi, I. \& Varhégyi, A. (1997). Radon monitoring in caves In: Radon Measurements by Etched Track Detectors, S. A. Durrani \& R. Ilić, (Eds.), pp. 261-283, World scientific Publishing Co. Pte. Ltd., ISBN 9810226667, Singapore.

Han, L., Zhuang, G., Sun, Y. \& Wang, Z. (2005). Local and non-local sources of airborne particulate pollution in Beijing. Science in China, Series B Chemistry, 48, pp. 253-264.

Hofmann, W. \& Koblinger, L. (1990). Monte Carlo modeling of aerosol deposition in human lungs. Part II: Deposition fractions and their sensitivity to parameter variation. Journal of Aerosol Science, 21, pp. 675-688.

Holmes, N. (2007). A review of particles formation events and growth in the atmosphere in the various environments and discussion of mechanistic implications. Atmospheric Environment, 41, pp. 2183-2201.

Holub, R. F., Raes, F., Van Dingenen, R. \& Vanmarcke, H. (1988). Deposition of aerosols and unattached radon daughters in different chambers; theory and experiment. Radiation Protection Dosimetry, 24, pp. 217-220.

Hopke, P. K. (1996). The initial atmospheric behaviour of radon decay products. Journal of Radioanalytical and Nuclear Chemistry, 203, pp. 533-375.

Hopke, P.K., Wasiolek, P, Montassier, N., Cavallo, A., Gadsby, K. \& Socolow, R. (1992). Measurement of activity-weighted size distributions of radon decay products in a normally occupied home. Radiation Protection Dosimetry, 45, pp. 329-331.

Humar, M., Šutej, T., Skvarč, J., Mljač, L., Radež, M. \& Ilić, R. (1992). Indoor and outdoor radon survey in Slovenia by etched track detectors. Radiation Protection Dosimetry, 45 , pp. 549-552.

International Commission on Radiological Protection (ICRP). (1994). Protection against radon222 at home and at work. ICRP Publication 65. Pergamon Press, Oxford.

Iskra, I., Kávási, N. \& Vaupotič, J. (2010). Nano aerosols in the Postojna Cave. Acta Carsologica, 39, pp. 523-528.

Kávási, N., Somlai, J., Szeiler, G., Szabó, B., Schafer, I. \& Kovács, T. (2010). Estimation of effective doses to cavers based on radon measurements carried out in seven caves of the Bakony Mountains in Hungary. Radiation Measurements, 45, pp. 1068-1071.

Kertész, Zs., Birbély-Kiss, I. \& Hunyadi, I. (1999). Study of aerosols collected in a speleotherapeutic cave situated below Budapest, Hungary, Nuclear Instruments and Methods in Physics Research B, 150, pp. 384-391.

Kulmala, M., Vehkamäki, H., Petäjä, T., Dal Maso, M., Lauri, A., Kerminen, V.-M., Birmili, W. \& McMurry, P. H. (2004). Formation and growth rates of ultrafine atmospheric particles: a review of observations. Aerosol Science, 35, pp. 142-176. 
Kumar, P., Fennell, P., Hayhurst, A. N. \& Britter, R. E. (2009). Street versus rooftop level concentrations of fine particles in a Cambridge street canyon. Boundary-Layer Meteorology, 131, pp. 3-18.

Kumar, P., Fennell, P. \& Robins, A. (2010a). Comparison of the behaviour of manufactured and other airborne nanoparticles and the consequences for prioritising research and regulation activities. Journal of Nanoparticle Research, 12, pp. 1523-1530.

Kumar, P., Robins, A., Vardoulakis, S. \& Britter, R. (2010b). A review of the characteristics of nanoparticles in the urban atmosphere and the prospects for developing regulatory controls. Atmospheric Environment, 44, 5035-5052.

Mackay, C. E. \& Henry, K. H. (2009). Environmental fate and transport, In: Nanotechnology and the Environment, pp. 123-154, CRC Press, Taylor \& Francis Group, ISBN 978-14200-6019-5, Boca Raton, USA.

Makkonen, U., Hellén, H., Anttila, P. \& Ferm, M. (2010). Size distribution and chemical composition of airborne particles in south-eastern Finland during different seasons and wildfire episodes in 2006. Science of the Total Environment, 408, pp. 644-651.

Markov, K. R. (1962). A rapid method to estimate radiation hazards related to radon decay products in air (in Russian). Atomnaya Energiya, 87, pp. 167-178.

Marsh, J.W., Birchall, A., Butterweck, G., Dorrian, M.-D., Huet, C., Ortega, X., Reineking, A., Tymen, G., Schuler, Ch., Vargas, A., Vessu, G. \& Wendt, J. (2002). Uncertainty analysis of the weighted equivalent lung dose per unit exposure to radon progeny in the home. Radiation Protection Dosimetry, 102, pp. 229-248.

Meisenberg, O. \& Tschiersch, J. (2009). Online measurement of unattached and total radon and thoron decay products. Applied Radiation and Isotopes, 67, pp. 843-848.

Mercer, T. T. (1976). The effect of particle size on the escape of recoiling RaB atoms from particulate surfaces. Health Physics, 31, pp. 173-175.

Minoura, H. \& Takeakwa, H. (2005). Observation of number concentrations of atmospheric aerosols and analysis of nanoparticles behaviour at an urban background area in Japan. Atmospheric Environment, 39, pp. 5806-5816.

Morawska, L, \& Jamriska M. (1996). Deposition of radon progeny on indoor surfaces. Journal of Aerosol Science, 27, pp. 305-312.

Morawska, L., Ristovski, Z., Jayarante E. R., Keogh, D. U. \& Ling, X. (2008). Ambient nano and ultrafine particles from motor vehicle emissions: characteristics, ambient processing and implications. Atmospheric Environment, 42, pp. 8113-8138.

Nel, A., Xia, T., Mädler, L. \& Li, N. (2006). Toxic potential of materials at the nanolevel. Science, 311, pp. 622-627.

Nero, Jr., A. V. (1988). Radon and its decay products in indoor air: an overview. In: Radon and its Decay Products in Indoor Air, W. W. Nazaroff, \& A. V. Nero, Jr., (Eds.), pp. 1-53, John Wiley \& Sons, New York; 1988. pp. 1-53.

Noble, A., Mukerjee, S., Gonzales, M., Rodes, C. E., Lawless, P. A., Natarajan, S., Myers, E. A., Norris, G. A., Smith, L. H., Ozkayanak, H. \& Neas, L. M. (2003). Continuous measurement of fine and ultrafine particulate matter, criteria pollutants and meteorological conditions in urban El Paso, Texas. Atmospheric Environment, 37, pp. 827-840.

Nowack, B. \& Bucheli, T. D. (2001). Occurrence, behaviour and effects of nanoparticles in the environment. Environment Pollution, 150, pp. 5-22. 
O’Dowd, C. D. \& Smith, M. H. (1997). Marine aerosol, sea-salt and the marine sulphur cycle: a short review. Atmospheric Environment, 31, pp. 73-80.

O’Dowd, C. D., Aalto, P., Hameri, K., Kulmala, M. \& Hoffmann, T. (2002). Aerosol formation: atmospheric particles from organic vapours. Nature, 416, pp. 497-498.

Oberdörster, G., Oberdörster, E. \& Oberdörster, J. (2005). Nanotoxicology: An emerging discipline evolving from studies of ultrafine particles. Environmental Health Perspectives, 113, pp. 823-839.

Pagelkopf, P. \& Porstendörfer, J. (2003). Neutralisation rate and the fraction of positive 218 Poclusters in air. Atmospheric Environment, 37, pp. 1057-1064.

Papastefanou, C. (2008). Radioactive Aerosols (1st Edition), Vol. 12 of the series Radioactivity in the Environment, M. S. Baxter (Ed.), Elsevier, ISBN 978-0-08-044075-0, Amsterdam.

Pashenko, S. E. \& Dublyansky, J. V. (1997). Generation of cave aerosols by alpha particles: critical evaluation of the hypothesis. Journal of Cave and Karst Studies, 59, pp. 103105.

Porstendörfer, J. \& Mercer, T. T. (1979). Influence of electric charge and humidity upon the diffusion coefficient of radon decay products. Health Physics, 37, pp. 191-199.

Porstendörfer, J. (1984). Behaviour of radon daughter products in indoor air. Radiation Protection Dosimetry, 7, 107-113.

Porstendörfer, J. \& Reineking, A. (1992). Indoor behaviour and characteristics of radon progeny. Radiation Protection Dosimetry, 45, pp. 303-311.

Porstendörfer, J. (1996). Radon: measurements related to dose. Environment International, 22 (Suppl. 1), pp. S563-S583.

Porstendörfer, J., Ch. Zock, Ch. \& Reineking, A. (2000). Aerosol size distribution of the radon progeny in outdoor air. Journal of Environmental Radioactivity, 51, pp. 37-48.

Porstendörfer, J. (2001). Physical parameters and dose factors of the radon and thoron decay products. Radiation Protection Dosimetry, 94, pp. 365-373.

Reineking, A., Becker, K. H. \& Porstendörfer, J. (1985). Measurements of the unattached fraction of radon daughters in homes. Science of the Total Environment, 45, pp. 261270.

Rovenská, K., Thinová, L., \& Ždímal, V. (2008). Assessment of the dose from radon and its decay products in the Bozkov dolomite cave. Radiation Protection Dosimetry, 130, pp. 34-37.

Sainz, C., Quindós, L. S., Fuente, I., Nicolás, J. \& Quindós, L. (2007). Analysis of the main factors affecting the evaluation of the radon dose in workplaces: The case of tourist caves. Journal of Hazardous Materials, 145, pp. 368-371.

Schery, S. D. (2001). Understanding Radioactive Aerosols and Their Measurement (1st Edition), Kluwer Academic Publishers, ISBN 0-7923-7068-6, Dordrecht, The Netherlands.

Schwikowski, M., Seibert, P., Baltensperger, U. \& Gaggeler, H. W. (1995). A study of an outstanding Sahara dust event at the high-alpine site Jungfraujoch, Switzerland. Atmospheric Environment, 29, pp. 1829-1842.

Shi, J. P., Evans, D. E., Khan, A. A. \& Harrison, R. M. (2001). Sources and concentration of nanoparticles (<10 nm diameter) in urban atmosphere. Atmospheric Environment, 35, pp. 1193-1202.

Shimo, M. \& Saito, H. (2000). Size distribution of radon progeny aerosols in indoor and outdoor air. Journal of Environmental Radioactivity, 51, pp. 49-57. 
Smerajec, M., Gregorič, A., Džeroski, S. \& Vaupotič, J. (2010). Continuous measurement of ultrafine particles at urban background site of Ljubljana. Book of abstracts of the $11^{\text {th }}$ European Meeting on Environmental Chemistry - EMEC 11, Portorož, Slovenia, December 8-11, 2010.

Solomon, S. B., Cooper, M. B., O'Brien, R. S. \& Wilkinson, L. (1992). Radon exposure in a limestone cave. Radiation Protection Dosimetry, 45, pp. 171-174.

Thinová, L., Berka, Z., Brandejsova, E., Ždímal, V. \& Milka, D. (2005). Effective dose calculation using radon daughters and aerosol particles measurement in Bozkov Dolomite Cave. International Congress Series, 1276, pp. 381-382.

Thinová, L., \& Burian, I. (2008). Effective dose assessment for workers in caves in the Czech Republic: experiments with passive radon detectors. Radiation Protection Dosimetry, 130, pp. 48-51.

Tokonami, S. (1999). Determination of the diffusion coefficient of unattached radon progeny with a graded screen array at the EML Radon/Aerosol chamber. Radiation Protection Dosimetry, 81, pp. 285-290.

Tokonami, S. (2000). Experimental verification of the attachment theory of radon progeny onto ambient aerosols. Health Physics, 78, pp. 74-79.

Tu, K. W., Knutson E. O. \& George, A. C. (1991). Indoor radon progeny aerosol size measurements in urban, suburban, and rural regions. Aerosol Science and Technology, 15, pp. 170-178.

Tu, K. W., Knutson E. O. \& George, A. C. (1994). Thoron versus radon: comparison of measured progeny aerosol size distributions. Aerosol Science and Technology, 20, pp. 266-274.

Turner, J. \& Colbeck, I. (2008). Physical and chemical properties of atmospheric aerosols, In: Environmental Chemistry of Aerosols, I. Colbeck, (Ed.), pp. 1-29, Blackwell Publishing Ltd., ISBN 978-1-4051-3919-9, Singapore.

United Nations Scientific Committee on the Effects of Atomic Radiation (UNSCEAR). (2000). Sources and Effects of Ionizing Radiation, UNSCEAR 2000 Report to the General Assembly, with Scientific Annexes, vol. 1, pp. 83-156, United Nations, New York.

Vakeva, M., Hameri, K., Kulmala, M., Lahdes, R., Ruuskanen, J. \& Laitinen, T. (1999). Street levels versus rooftop concentrations of submicron aerosol particles and gaseous pollutants in an urban street canyon. Atmospheric Environment, 33, pp. 1385-1397.

Vanmarcke, H., Landsheere, C., Van Dingenen, R. \& Poffijn, A. (1991). Influence of turbulence on the deposition rate constant of the unattached radon decay products. Aerosol Science and Technology, 14, pp. 257-265.

Vaupotič, J., Csige, I., Radolić, V., Hunyadi, I., Planinić, J., \& Kobal, I. (2001). Methodology of radon monitoring and dose estimates in Postojna Cave, Slovenia. Health Physics, 80, pp. 142-147.

Vaupotič, J. \& Kobal, I. (2006). Effective doses in schools based on nanosize radon progeny. Atmospheric Environment, 40, pp. 7494-7507.

Vaupotič, J. (2007). Nano-size radon short-lived progeny aerosols in Slovenian kindergartens in wintertime. Chemosphere, 2007, 69, pp. 856-863.

Vaupotič, J. (2008a). Comparison of various methods of estimating radon dose in underground workplaces in wineries. Radiation and Environmental Biophysics, 47, pp. 527-534. 
Vaupotič, J. (2008b). Nanosize radon short-lived decay products in the air of the Postojna Cave. Science of the Total Environment, 393, pp. 27-38.

Vaupotič, J. (2010). Radon levels in karst caves in Slovenia. Acta Carsologica, 39, pp. 503-512.

Wang, F., Costabileb, F., Li, H., Fang, D. \& Alligrini, I. (2010). Measurements of ultrafine particle size distribution near Rome. Atmospheric Research, 98, pp. 69-77.

Wang, Y., Hopke, P. K., Chalupa, D. C. \& Utell, M. J. (2010). Long-term study of urban ultrafine particles and other pollutants. Atmospheric Environment, doi: 10.1016/j.atmosenv.2010.08.022.

Wen, C. S. (1996). The Fundamentals of Aerosol Dynamics, (1 ${ }^{\text {st }}$ Edition), World Scientific Publishing Co. Pte. Ltd., ISBN 9810226616, Singapore.

Young, L.-H. \& Keeler, G. J. (2007). Summertime ultrafine particles in urban and industrial air: Aitken and nucleation mode particle events. Aerosol and Air Quality Research, 7, pp. 379-402. 


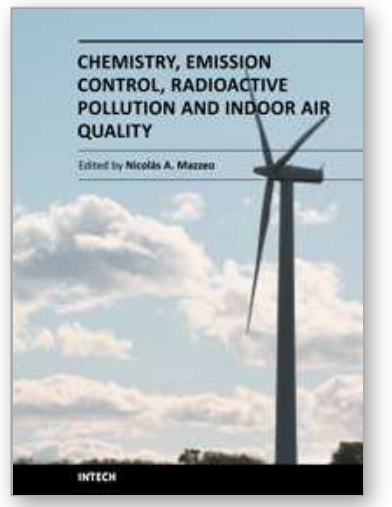

\author{
Chemistry, Emission Control, Radioactive Pollution and Indoor Air \\ Quality \\ Edited by Dr. Nicolas Mazzeo
}

ISBN 978-953-307-316-3

Hard cover, 680 pages

Publisher InTech

Published online 27, July, 2011

Published in print edition July, 2011

The atmosphere may be our most precious resource. Accordingly, the balance between its use and protection is a high priority for our civilization. While many of us would consider air pollution to be an issue that the modern world has resolved to a greater extent, it still appears to have considerable influence on the global environment. In many countries with ambitious economic growth targets the acceptable levels of air pollution have been transgressed. Serious respiratory disease related problems have been identified with both indoor and outdoor pollution throughout the world. The 25 chapters of this book deal with several air pollution issues grouped into the following sections: a) air pollution chemistry; b) air pollutant emission control; c) radioactive pollution and d) indoor air quality.

\title{
How to reference
}

In order to correctly reference this scholarly work, feel free to copy and paste the following:

Janja Vaupotič (2011). Nano Particles Including Radon Decay Products in Ambient Air, Chemistry, Emission Control, Radioactive Pollution and Indoor Air Quality, Dr. Nicolas Mazzeo (Ed.), ISBN: 978-953-307-316-3, InTech, Available from: http://www.intechopen.com/books/chemistry-emission-control-radioactive-pollutionand-indoor-air-quality/nano-particles-including-radon-decay-products-in-ambient-air

\section{INTECH}

open science | open minds

\section{InTech Europe}

University Campus STeP Ri

Slavka Krautzeka 83/A

51000 Rijeka, Croatia

Phone: +385 (51) 770447

Fax: +385 (51) 686166

www.intechopen.com

\section{InTech China}

Unit 405, Office Block, Hotel Equatorial Shanghai

No.65, Yan An Road (West), Shanghai, 200040, China

中国上海市延安西路65号上海国际贵都大饭店办公楼405单元

Phone: +86-21-62489820

Fax: $+86-21-62489821$ 
(C) 2011 The Author(s). Licensee IntechOpen. This chapter is distributed under the terms of the Creative Commons Attribution-NonCommercialShareAlike-3.0 License, which permits use, distribution and reproduction for non-commercial purposes, provided the original is properly cited and derivative works building on this content are distributed under the same license. 